\title{
Predicting secondary organic aerosol phase state and viscosity and its effect on multiphase chemistry in a regional-scale air quality model
}

\author{
Ryan Schmedding $^{1, \mathrm{a}, \star}$, Quazi Z. Rasool ${ }^{1, \mathrm{~b}, \star}$, Yue Zhang ${ }^{1,4}$, Havala O. T. Pye ${ }^{1,2}$, Haofei Zhang ${ }^{3}$, Yuzhi Chen ${ }^{1}$, \\ Jason D. Surratt ${ }^{1}$, Felipe D. Lopez-Hilfiker ${ }^{5, \mathrm{c}}$, Joel A. Thornton ${ }^{5}$, Allen H. Goldstein ${ }^{6,7}$, and William Vizuete ${ }^{1}$ \\ ${ }^{1}$ Department of Environmental Science and Engineering, The University of North Carolina at Chapel Hill, \\ Chapel Hill, NC 27516, USA \\ ${ }^{2}$ Office of Research and Development, Environmental Protection Agency, Research Triangle Park, \\ Durham, NC 27709, USA \\ ${ }^{3}$ Department of Chemistry, University of California at Riverside, Riverside, CA 92521, USA \\ ${ }^{4}$ Aerodyne Research, Inc., Billerica, MA 01821, USA \\ ${ }^{5}$ Department of Atmospheric Sciences, University of Washington, Seattle, WA 98195, USA \\ ${ }^{6}$ Department of Environmental Science, Policy, and Management, University of California, Berkeley, CA 94720, USA \\ ${ }^{7}$ Department of Civil and Environmental Engineering, University of California, Berkeley, CA 94720, USA \\ ${ }^{a}$ present address: Department of Atmospheric and Oceanic Science, McGill University, Montreal, H3A 2K6, Canada \\ b present address: Pacific Northwest National Laboratory, Richland, WA 99354, USA \\ ${ }^{c}$ present address: Tofwerk AG, 3600 Thun, Switzerland \\ These authors contributed equally to this work.
}

Correspondence: William Vizuete (vizuete@unc.edu)

Received: 5 October 2019 - Discussion started: 7 November 2019

Revised: 29 May 2020 - Accepted: 14 June 2020 - Published: 16 July 2020

\begin{abstract}
Atmospheric aerosols are a significant public health hazard and have substantial impacts on the climate. Secondary organic aerosols (SOAs) have been shown to phase separate into a highly viscous organic outer layer surrounding an aqueous core. This phase separation can decrease the partitioning of semi-volatile and low-volatile species to the organic phase and alter the extent of acidcatalyzed reactions in the aqueous core. A new algorithm that can determine SOA phase separation based on their glass transition temperature $\left(T_{\mathrm{g}}\right)$, oxygen to carbon $(\mathrm{O}: \mathrm{C})$ ratio and organic mass to sulfate ratio, and meteorological conditions was implemented into the Community Multiscale Air Quality Modeling (CMAQ) system version 5.2.1 and was used to simulate the conditions in the continental United States for the summer of 2013. SOA formed at the ground/surface level was predicted to be phase separated with core-shell morphology, i.e., aqueous inorganic core surrounded by organic coating $65.4 \%$ of the time during the
\end{abstract}

2013 Southern Oxidant and Aerosol Study (SOAS) on average in the isoprene-rich southeastern United States. Our estimate is in proximity to the previously reported $\sim 70 \%$ in literature. The phase states of organic coatings switched between semi-solid and liquid states, depending on the environmental conditions. The semi-solid shell occurring with lower aerosol liquid water content (western United States and at higher altitudes) has a viscosity that was predicted to be $10^{2}-10^{12} \mathrm{Pas}$, which resulted in organic mass being decreased due to diffusion limitation. Organic aerosol was primarily liquid where aerosol liquid water was dominant (eastern United States and at the surface), with a viscosity $<10^{2}$ Pas. Phase separation while in a liquid phase state, i.e., liquid-liquid phase separation (LLPS), also reduces reactive uptake rates relative to homogeneous internally mixed liquid morphology but was lower than aerosols with a thick viscous organic shell. The sensitivity cases performed with different phase-separation parameterization and dissolution 
rate of isoprene epoxydiol (IEPOX) into the particle phase in CMAQ can have varying impact on fine particulate matter $\left(\mathrm{PM}_{2.5}\right)$ organic mass, in terms of bias and error compared to field data collected during the 2013 SOAS. This highlights the need to better constrain the parameters that govern phase state and morphology of SOA, as well as expand mechanistic representation of multiphase chemistry for non-IEPOX SOA formation in models aided by novel experimental insights.

\section{Introduction}

Particulate matter (PM) is one of six criteria pollutants regulated by the United States Environmental Protection Agency (EPA)'s National Ambient Air Quality Standards (NAAQS), established by the 1970 Clean Air Act. There are two categories of PM regulated by NAAQS: fine PM $\left(\mathrm{PM}_{2.5}\right)$ with particle diameter less than $2.5 \mu \mathrm{m}$ and coarse $\mathrm{PM}\left(\mathrm{PM}_{10}\right)$ with particle diameter up to $10 \mu \mathrm{m}$. PM has adverse effects on the global climate (Carslaw et al., 2013; Grandey et al., 2018; L. A. Lee et al., 2016; Regayre et al., 2015). PM $_{2.5}$ also represents a substantial public health risk due to its association with increased overall mortality, due to cardiorespiratory diseases (Hwang et al., 2017; Jaques and Kim, 2000; Zanobetti and Schwartz, 2009). It has been estimated that 20\%-60\% of $\mathrm{PM}_{2.5}$ are comprised of organic aerosols (OAs) (Docherty et al., 2008). These pollutant species are either directly emitted primary organic aerosols (POAs) or secondary organic aerosols (SOAs), which form when volatile organic compounds (VOCs) undergo chemical reactions that reduce their volatility to the point that they partition into the aerosol phase (Zhang et al., 2007) or react heterogeneously with the existing particles (Riva et al., 2019). Studies have found that SOA tends to form the bulk of observed OA around the world (Nozière et al., 2015). The VOCs that form SOA may be either from biogenic or anthropogenic sources and can vary both spatially and temporally to areas as confined as the community level (Yu et al., 2014).

Recent studies have shown that SOA may undergo phase separation under atmospherically relevant conditions resulting in different morphologies. These observations have included a "partially engulfed" organic-inorganic morphology; an emulsified or "island" morphology, where discrete pockets of SOA dot a larger inorganic particle; and a "core-shell" morphology, characterized by an organic-rich outer "shell" and aqueous inorganic "core" (Freedman, 2017; O'Brien et al., 2015; Price et al., 2015; Renbaum-Wolff et al., 2016; Song et al., 2015, 2016; You et al., 2012; Y. Zhang et al., 2015, 2018). Pye et al. (2018) applied the Aerosol InorganicOrganic Mixtures Functional groups Activity Coefficients (AIOMFAC) model (Zuend et al., 2008) to predict the thermodynamic favorability of phase separation in SOA using a box model and found that aerosols over the southeastern United States may be phase separated as frequently as $70 \%$ of the time. Pye et al. (2017) used the ratio of organic matter to organic carbon (OM : OC) and the ambient relative humidity $(\mathrm{RH})$ to predict phase-separation frequencies. They found that phase separation was common at lower RH in urban areas with low OM : OC, but lower phase-separation frequencies in rural areas were attributed to increasing OM : OC except for late mornings when phase-separation frequency increased due to low RH.

When aerosols form a core-shell morphology, experimentally observed viscosities of the outer organic-rich shell and inner electrolyte-rich core have been shown to differ by up to 3 orders of magnitude, resulting in possible diffusion limitations on reactive uptake (Ullmann et al., 2019). It has also been shown that the viscosity of the organic-rich shell and subsequently diffusivity of gaseous particles through it $\left(D_{\text {org }}\right)$ may vary as a function of SOA composition (Grayson et al., 2017). Laboratory experiments have been conducted to measure the viscosity of SOA using poke-flow and bead mobility techniques (Reid et al., 2018; Renbaum-Wolff et al., 2013; Song et al., 2015, 2016). These studies have found that SOAs formed from anthropogenic precursors, such as benzene, toluene and xylene, have similar $D_{\text {org }}$ values in the realm of $10^{-14}-10^{-16} \mathrm{~m}^{2} \mathrm{~s}^{-1}$ (Grayson et al., 2016; Song et al., 2015, 2016, 2018). Similar studies on biogenic SOA comprised of $\alpha$-pinene oxidation products found that its measured viscosities and calculated diffusion coefficients are lower than those of anthropogenic SOA by as much as 2 orders of magnitude in comparable conditions (Song et al., 2016, 2018; Zhang et al., 2015).

The most abundantly emitted biogenic VOC is isoprene (2methyl-1,3-butadiene), with average annual global emissions totaling approximately $500-750 \mathrm{Tg} \mathrm{Cyr}^{-1}$ (Guenther et al., 2006; Liao et al., 2015). Isoprene is known to react with hydroxyl $(\mathrm{OH})$ radicals under low- $\mathrm{NO}_{x}\left(=\mathrm{NO}+\mathrm{NO}_{2}\right)$ conditions to form isoprene hydroxyhydroperoxides (ISOPOOH) (Jacobs et al., 2014; Krechmer et al., 2015). If the reaction pathway continues with $\mathrm{OH}$, ISOPOOH will react again to form isoprene epoxydiol (IEPOX) (Bates et al., 2014; Paulot et al., 2009; Surratt et al., 2010). It is possible for IEPOX to form products with sufficiently low volatility to form SOA via a reactive uptake onto acidified sulfate seed particles (Bondy et al., 2018; Surratt et al., 2006, 2007, 2010). IEPOXderived SOA have been observed to account for up to $36 \%$ of biogenic SOA in the southeastern United States during the summer (Budisulistiorini et al., 2016). Given the importance of this pathway, there has been increased focus on the phase state of particles and its impact on reactive uptake (Budisulistiorini et al., 2017).

Prior measurements of isoprene-derived SOA suggested that it would not be viscous enough to exhibit diffusion limitations. There is still much uncertainty with these measurements as those particles are mainly formed through nucleation of semi-volatile species (Song et al., 2015). IEPOXderived SOA in the southeastern United States is found to exhibit higher volatility than the remaining bulk OA, with 
saturation vapor pressures for IEPOX-derived SOA being 2 to 8 orders of magnitude larger than the remaining bulk OA. However, IEPOX-derived SOA has a low overall volatility, with evaporation timescales $>100 \mathrm{~h}$ under atmospherically relevant conditions (Lopez-Hilfiker et al., 2016). Specifically, acid-driven multiphase chemistry of IEPOX with inorganic sulfate aerosol results in a significant yield of organosulfates that have potentially higher viscosities (Riva et al., 2019). Furthermore, RH (Huang et al., 2018; Pajunoja et al., 2014; Song et al., 2015, 2016; Zhang et al., 2015, 2018a), temperature (Maclean et al., 2017), degree of oligomerization and mass loading (Grayson et al., 2016) also impact particle viscosity. Higher RHs may result in more water to partition into the particle and act as a plasticizer which decreases its viscosity (Song et al., 2015, 2016, 2018; Zhang et al., 2011). Higher temperatures also increase the diffusion coefficient (Chenyakin, 2015). The degree of oligomerization increases the viscosity of SOA and therefore reduces its $D_{\text {org }}$ as well (Grayson et al., 2017). The reduced transport of semi- or low-volatile gas species such as IEPOX onto particles also highlights the effects of phase separation on aerosol formation by decreasing reactive uptake of IEPOX (Gaston et al., 2014). This is due to increased resistance to diffusion of IEPOX through the SOA coating (Y. Zhang et al., 2018). The experimental data provided from previous studies highlight the urgency of incorporating those results into regional and global models to accurately predict the effects of phase states on aerosol formation in the ambient environment. A recent study by Schmedding et al. (2019) used a dimensionless (0-D) box model for phase-separated SOA formation at the Look Rock site during the 2013 Southern Oxidant and Aerosol Study (SOAS). Our prior work found that the inclusion of a phase-separation parameter could either inhibit SOA due to diffusion limitations in the separated organic phase or increase it by concentrating the electrolytes into the aqueous core, leading to faster acid-catalyzed reactions. This resulted in decreasing normalized mean error (NME) of the model from $83.4 \%$ to $77.9 \%$ and the normalized mean bias (NMB) from $-66.2 \%$ to $-36.3 \%$ compared to a previous work simulating the same dataset that assumed homogeneous aerosol (Budisulistiorini et al., 2016). The aforementioned model study (Schmedding et al., 2019) highlighted the significant impact of an organic coating layer on IEPOX-derived SOA formation but lacked any quantification of conditions that result in phase separation creating such organic coating and its phase state.

The inclusion of an explicit reaction pathway for the reactive uptake of acid-catalyzed IEPOX-derived SOA in both regional- and global-scale chemical transport models (CTMs), such as the Community Multi-Scale Air Quality Model (CMAQ v5.2.1) and the Goddard Earth Observing System (GEOS-Chem v11-02-rc), has substantially improved the performance of predicted SOA yields (Marais et al., 2016; Pye et al., 2013, 2017). These models do not include parameters in their aerosol algorithms that account for aerosol morphology or phase separation and its impact on SOA formation (Marais et al., 2016; Pye et al., 2017, 2018), which can lead to potential deviations of aerosol quantification. This work systematically examines formation of coatings comprised of OA derived from a mixture of biogenic and anthropogenic compounds. Besides predicting frequencies of core-shell morphology, this work explores how organic coating impacts acid-catalyzed multiphase reactions of IEPOX by implementing parameterizations to determine the viscosity and phase state of particles (liquid or glassy) in CMAQ and simulating for the continental United States.

\section{Methods}

\subsection{Phase state and its impact on reactive uptake: overview}

Particles that are in a liquid-like state may either be an internal homogeneous mixture, or they can be phase separated in a core-shell morphology with inorganic-rich core and the organic-rich shell also referred to as liquid-liquid phase separation (LLPS). The occurrence of LLPS depends on the average $\mathrm{O}: \mathrm{C}$ ratio, organic mass to sulfate ratio, ambient temperature and ambient RH (Song et al., 2018; Zuend and Seinfeld, 2012). Organic constituents of an aerosol may also exhibit a solid-like glassy phase state when the ambient temperature is below the glass transition temperature $\left(T_{\mathrm{g}}\right)$, which is a function of RH and the aerosol composition (DeRieux et al., 2018). A liquid phase state occurs when the $T_{\mathrm{g}}$ is lower than ambient temperature. The difference in viscosity $\left(\eta_{\text {org }}\right)$ of the organic-rich coating, below and above the $T_{\mathrm{g}}$, may be as high as 8 orders of magnitude (Marsh et al., 2018). Thus, $T_{\mathrm{g}}$ can be used to determine when aerosols are in a highly viscous glassy state $\left(\eta_{\text {org }} \geq 10^{12} \mathrm{Pas}\right)$, a semi-solid state $(100 \leq$ $\eta_{\text {org }}<10^{12} \mathrm{Pas}$ ) or a liquid state $\left(\eta_{\text {org }}<100 \mathrm{Pas}\right)$ (Marcolli et al., 2004; Martin, 2000). Aerosols in a highly viscous or a semi-solid state can be homogeneous or phase separated in a core-shell morphology, similar to particles with a liquid-like state. For this study, we also ran a sensitivity simulation to see the impact if highly viscous particles were phase separated at all times (refer to Sect. 2.6). The need for this sensitivity is based on recent observations showing higher-thananticipated rebound fractions in OA particles with viscosities $>10^{2} \mathrm{Pas}$, implying a highly viscous particle that can likely exhibit diffusive limitations in reactive uptake (Reid et al., 2018). These viscous aerosols can be assumed to be in an amorphous solid phase, homogeneous or phase separated, but unlike liquid particles, they can only dissipate energy by rebounding, and criteria governing phase separation in them is not well constrained (Bateman et al., 2015a, b, 2017; Reid et al., 2018; Virtanen et al., 2010). The specific conditions under which a particle will form a glassy rather than liquid-like organic shell are unclear but thought to be driven by the same underlying physical properties that drive 
viscosity. This led to a sensitivity simulation with the consideration that semi-solid or glassy particles would inherently adopt a core-shell morphology. This sensitivity case can be thought of as an upper bound on the frequency of particles separating into core-shell morphology. For the primary phase-separation criteria to be broader, it was not assumed that a semi-solid state is always phase separated, and instead the LLPS criteria were applied for conditions that produce a low aerosol water content (refer to Sect. 2.3).

Phase state of an organic shell impacts reactive uptake by affecting the diffusivity of a species through this outer organic shell $\left(D_{\text {org }}\right)$. $D_{\text {org }}$ can be related to the viscosity of the organic shell $\left(\eta_{\text {org }}\right)$ using the Stokes-Einstein equation, as shown in Eq. (1) (Ullmann et al., 2019):

$D_{\text {org }}=\frac{k_{\mathrm{b}} T}{6 \pi \eta_{\text {org }} r_{\text {diffusive }}}$,

where $k_{\mathrm{b}}$ is the Boltzmann constant, $T$ is the ambient temperature, $\eta_{\text {org }}$ is the organic shell viscosity, and $r_{\text {diffusive }}$ is the hydrodynamic radius of the molecule diffusing through the viscous organic shell.

\subsection{Determining the glass transition temperature $\left(T_{\mathrm{g}, \text { org }}\right)$}

The combined $T_{\mathrm{g} \text {,org }}$ for anthropogenic species, biogenic species and aerosol water associated with them was found using a modified version of the Gordon-Taylor mixing rule, as represented by Eq. (2) (DeRieux et al., 2018; Gordon and Taylor, 1952):

$T_{\mathrm{g}, \text { org }}=\frac{\left(w_{\mathrm{s}} T_{\mathrm{g}, \mathrm{w}}+\frac{1}{k_{\mathrm{GT}}}\left(w_{\mathrm{a}} T_{\mathrm{g}, \mathrm{a}}+w_{\mathrm{b}} T_{\mathrm{g}, \mathrm{b}}\right)\right)}{w_{\mathrm{s}}(\mathrm{RH})+\frac{1}{k_{\mathrm{GT}}}\left(w_{\mathrm{a}}+w_{\mathrm{b}}\right)}$,

where $T_{\mathrm{g}, \mathrm{w}}$ is the glass transition temperature of water (137 K) (Koop et al., 2011). $T_{\mathrm{g}, \mathrm{a}}$ and $T_{\mathrm{g}, \mathrm{b}}$ are the respective glass transition temperatures $(\mathrm{K})$ for the anthropogenic (also includes all combustion-generated POA in addition to VOC-derived SOA; see Table 1) and biogenic (only includes VOC-derived SOA; see Table 1) fractions of OA. $K_{\mathrm{GT}}$ is the Gordon-Taylor constant, which is assumed to be 2.5 based on Koop et al. (2011). $w_{\mathrm{a}}$ and $w_{\mathrm{b}}$ are the mass fractions of anthropogenic and biogenic OA species, respectively. $w_{\mathrm{S}}(\mathrm{RH})$ or simply $w_{\mathrm{s}}$ is the mass fraction of organic aerosol water.

For this work, it was assumed that $10 \%$ of the aerosol water was present in the organic shell, which is a lower bound estimate of the range of organic water reported by Pye et al. (2017). Approximately $10 \%$ of total aerosol water is associated with the organic phase during daytime when IEPOX chemistry is more prevalent as indicated by the observations collected during the 2013 SOAS campaign (Guo et al., 2015). To best replicate daytime IEPOX chemistry, the $10 \%$ value was chosen under the assumption that the underprediction of nighttime organic water would negligibly impact overall
IEPOX-derived SOA. Naturally, this is not applicable for the rest of multiphase chemistry and should be addressed accordingly in future work. In CMAQ v5.2.1, the total aerosol water is predicted by ISORROPIA and only associated with inorganic electrolytes such as ammonium bisulfate (Pye et al., 2017). As represented by Eq. (3), the $w_{\mathrm{s}}$ along with the $w_{\mathrm{a}}$ and $w_{\mathrm{b}}$ make up the organic water component of the aerosol and add up to 1:

$w_{\mathrm{s}}=1-\left(w_{\mathrm{a}}+w_{\mathrm{b}}\right)$.

Shiraiwa et al. (2017) used 179 organic species to fit a relationship between $T_{\mathrm{g}}$, the molar mass $(M)$ and $\mathrm{O}: \mathrm{C}$ ratio (Shiraiwa et al., 2017) . Following the same relationship as in Eq. (4), the respective glass transition temperatures for the anthropogenic and biogenic fractions $\left(T_{\mathrm{g}, \mathrm{a}}\right.$ and $\left.T_{\mathrm{g}, \mathrm{b}}\right)$ were calculated using the weighted average molar mass $\left(M_{x}\right)$ and $\mathrm{O}: \mathrm{C}$ ratio $\left((\mathrm{O}: \mathrm{C})_{x}\right)$ for all individual anthropogenic and biogenic species addressed in CMAQ (see Table 1), where $x$ refers to anthropogenic (a) or biogenic (b) OA and $i$ refers to individual species:

$$
\begin{aligned}
T_{\mathrm{g}, x} \text { or } T_{x} & =-21.57+1.51 M_{x}-0.0017 M_{x}^{2} \\
& +131.4(\mathrm{O}: \mathrm{C})_{x}-0.25 M_{x}(\mathrm{O}: \mathrm{C})_{x},
\end{aligned}
$$

where

$$
\begin{aligned}
M_{x} & =\sum\left(w_{\mathrm{i}, x} M_{\mathrm{i}, x}\right) ;(\mathrm{O}: \mathrm{C})_{x} \\
& =\sum\left(w_{\mathrm{i}, x}(\mathrm{O}: \mathrm{C})_{\mathrm{i}, x}\right) ; w_{\mathrm{i}, x} \\
& =\frac{\text { mass concentration }_{\mathrm{i}, x}}{\text { total mass concentration }_{x}} .
\end{aligned}
$$

When the ambient temperature is below the $T_{\mathrm{g}, \text { org }}$, the viscosity of the coating ( $\eta_{\text {org }}$ ) is assumed to remain constant at $10^{12} \mathrm{Pas}$. When the ambient temperature is greater than or equal to the calculated $T_{\mathrm{g}, \text { org }}$, the viscosity of the organic shell is calculated using a modified Vogel-Tamman-Fulcher equation (DeRieux et al., 2018; Fulcher, 1925; Tamman and Hesse, 1926; Vogel, 1921), as shown in Eq. (5) with experimentally fitted parameters as shown in Eqs. (6) and (7):

$$
\begin{aligned}
& \log _{10}\left(\eta_{\mathrm{org}}\right)=-5+0.434 \frac{T_{0} D}{T-T_{0}} \\
& T_{0}=\frac{39.17 T_{\mathrm{g}, \mathrm{org}}}{D+39.17} \\
& D=14.4-2.3(\mathrm{O}: \mathrm{C})_{\mathrm{avg}} .
\end{aligned}
$$

$T$ is the ambient temperature (K), $T_{0}$ is an experimentally fitted parameter of Eq. (5) that varies as a function of $T_{\mathrm{g}, \text { org }}$ and the fragility parameter $D$, which is a function of the $\mathrm{O}: \mathrm{C}$ ratio (DeRieux et al., 2018; Zhang et al., 2019). (O : C) avg refers to the overall OA (including both POA - all anthropogenic and SOA - anthropogenic and biogenic; see Table 1) $\mathrm{O}: \mathrm{C}$ ratio given by CMAQ.

The effective diffusion coefficient for IEPOX through the organic coating $\left(D_{\text {org }}\right)$ was then calculated using the StokesEinstein equation (refer to Eq. 1), assuming that $r_{\text {diffusive }}=$ $1 \mathrm{~nm}$ (Evoy et al., 2019; Ullmann et al., 2019). 
Table 1. CMAQ-defined aerosol phase species (Pye et al., 2017; Murphy et al., 2017) used in the calculation of the predicted organic-phase parameter (overall SOA viscosity - $\eta_{\text {org }}$ ) and their respective organic mass to organic carbon ratio (OM : OC) (Pye et al., 2017), atomic oxygen to carbon ratio $(\mathrm{O}: \mathrm{C})$, molar weight (Pye et al., 2017) and predicted individual glass transition temperature $\left(T_{\mathrm{g}}\right)$ and viscosity at standard temperature.

\begin{tabular}{|c|c|c|c|c|c|c|c|}
\hline $\begin{array}{l}\text { Species } \\
\text { name }\end{array}$ & Description & Source & $\begin{array}{r}\mathrm{OM}: \mathrm{OC} \\
\text { ratio }\end{array}$ & $\begin{array}{l}\mathrm{O}: \mathrm{C} \\
\text { ratio }\end{array}$ & $\begin{array}{l}\text { Molar weight } \\
\qquad\left(\mathrm{g} \mathrm{mole}^{-1}\right)\end{array}$ & $\begin{array}{r}\text { Predicted } \\
T_{\mathrm{g}}(\mathrm{K})\end{array}$ & $\begin{array}{r}\text { Predicted } \eta_{\text {org }} \text { at } T=298 \mathrm{~K} \\
\text { and ALW }=0(\mathrm{Pas})\end{array}$ \\
\hline AALK1 & SV alkane VOC SOA & ANTH & 1.56 & 0.315 & 225 & 256 & $7.54 \times 10^{9}$ \\
\hline AALK2 & SV alkane VOC SOA & ANTH & 1.42 & 0.203 & 205.1 & 233 & $5.34 \times 10^{7}$ \\
\hline ABNZ1 & SV high- $\mathrm{NO}_{x} \mathrm{SOA}$ product from benzene & ANTH & 2.68 & 1.211 & 161 & 289 & $1.67 \times 10^{14}$ \\
\hline ABNZ2 & SV high-NO $\mathrm{NOA}_{x}$ product from benzene & ANTH & 2.23 & 0.851 & 134 & 234 & $2.66 \times 10^{7}$ \\
\hline ABNZ3 & LV low-NO $\mathrm{NOA}_{x}$ product from benzene & ANTH & 3.00 & 1.467 & 180 & 322 & $1.00 \times 10^{12}$ \\
\hline AGLY & Glyoxal/methylglyoxal SOA & $\mathrm{BIOG}$ & 2.13 & 0.771 & 66.4 & 160 & $1.71 \times 10^{3}$ \\
\hline AISO1 & SV SOA product from isoprene & BIOG & 2.20 & 0.827 & 132.0 & 230 & $1.20 \times 10^{7}$ \\
\hline $\mathrm{AISO} 2$ & HV SOA product from isoprene & $\mathrm{BIOG}$ & 2.23 & 0.851 & 133.0 & 233 & $2.26 \times 10^{7}$ \\
\hline AISO3 & $\begin{array}{l}\text { Acid-catalyzed isoprene SOA compounds (2- } \\
\text { methyltetrols plus IEPOX organosulfate) }\end{array}$ & BIOG & 2.80 & 1.307 & 168.2 & 301 & $1.00 \times 10^{12}$ \\
\hline ALVOO1 & LV oxidized combustion organic compounds & ANTH & 2.27 & 0.883 & 136 & 238 & $6.59 \times 10^{7}$ \\
\hline $\mathrm{ALVOO} 2$ & LV oxidized combustion organic compounds & ANTH & 2.06 & 0.715 & 136 & 222 & $3.97 \times 10^{6}$ \\
\hline AOLGA & $\begin{array}{l}\text { Oligomer products of anthropogenic SOA com- } \\
\text { pounds }\end{array}$ & ANTH & 2.50 & 1.067 & 206 & 303 & $1.00 \times 10^{12}$ \\
\hline AOLGB & $\begin{array}{l}\text { Oligomer products of biogenic SOA com- } \\
\text { pounds }\end{array}$ & BIOG & 2.10 & 0.747 & 248 & 300 & $1.00 \times 10^{12}$ \\
\hline AORGC & Glyoxal and methylglyoxal SOA & BIOG & 2.00 & 0.667 & 177 & 251 & $1.33 \times 10^{9}$ \\
\hline APAH1 & SV high-NO $\mathrm{NOA}_{x}$ product from PAHs & ANTH & 1.63 & 0.371 & 195.6 & 239 & $1.58 \times 10^{8}$ \\
\hline APAH2 & SV high-NO $\mathrm{SOA}_{x}$ product from PAHs & ANTH & 1.49 & 0.259 & 178.7 & 216 & $2.80 \times 10^{6}$ \\
\hline APAH3 & LV low-NO ${ }_{x}$ SOA product from PAHs & ANTH & 1.77 & 0.483 & 212.2 & 260 & $1.97 \times 10^{10}$ \\
\hline APCSO & Potential combustion SOA & ANTH & 2.00 & 0.667 & 170 & 245 & $3.91 \times 10^{8}$ \\
\hline ASQT & SV SOA from sesquiterpenes & $\mathrm{BIOG}$ & 1.52 & 0.283 & 135 & 179 & $1.87 \times 10^{4}$ \\
\hline ASVOO1 & SV oxidized combustion organic products & ANTH & 1.88 & 0.571 & 135 & 207 & $4.69 \times 10^{5}$ \\
\hline ASVOO2 & SV oxidized combustion organic products & ANTH & 1.73 & 0.451 & 135 & 195 & $1.10 \times 10^{5}$ \\
\hline ASVOO3 & SV oxidized combustion organic compounds & ANTH & 1.60 & 0.347 & 134 & 184 & $3.19 \times 10^{4}$ \\
\hline AIVPO1 & $\begin{array}{l}\text { Intermediate-volatility primary organic com- } \\
\text { pounds }\end{array}$ & ANTH & 1.17 & 0.003 & 266 & 260 & $3.22 \times 10^{10}$ \\
\hline ALVPO1 & LV primary organic compounds & ANTH & 1.39 & 0.179 & 218 & 241 & $2.58 \times 10^{8}$ \\
\hline ASVPO1 & SV primary organic compounds & ANTH & 1.32 & 0.123 & 230 & 245 & $7.00 \times 10^{8}$ \\
\hline ASVPO2 & SV primary organic compounds & ANTH & 1.26 & 0.075 & 241 & 249 & $1.86 \times 10^{9}$ \\
\hline ASVPO3 & SV primary organic compounds & ANTH & 1.21 & 0.035 & 253 & 254 & $6.63 \times 10^{9}$ \\
\hline ATOL1 & SV high-NO ${ }_{x}$ toluene SOA & ANTH & 2.26 & 0.875 & 163 & 259 & $8.17 \times 10^{9}$ \\
\hline ATOL2 & SV high-NO ${ }_{x}$ toluene SOA & ANTH & 1.82 & 0.523 & 175 & 23 & $7.25 \times 10^{7}$ \\
\hline ATOL3 & LV low-NO ${ }_{x}$ toluene SOA & ANTH & 2.70 & 1.227 & 194 & 309 & $1.00 \times 10^{12}$ \\
\hline ATRP1 & SV SOA product from monoterpenes & BIOG & 1.84 & 0.539 & 177 & 239 & $1.30 \times 10^{8}$ \\
\hline ATRP2 & HV SOA product from monoterpenes & BIOG & 1.83 & 0.531 & 198 & 254 & $3.93 \times 10^{9}$ \\
\hline AXYL1 & SV high-NO ${ }_{x}$ SOA product from xylene & ANTH & 2.42 & 1.003 & 174 & 278 & $3.16 \times 10^{12}$ \\
\hline AXYL2 & SV high-NO ${ }_{x}$ SOA product from xylene & ANTH & 1.93 & 0.611 & 185 & 252 & $1.85 \times 10^{9}$ \\
\hline AXYL3 & LV low-NO $\mathrm{NOA}_{x}$ product from xylene & ANTH & 2.30 & 0.907 & 218 & 297 & $1.43 \times 10^{16}$ \\
\hline
\end{tabular}


Table 2. Rate constants used to calculate the effective first-order rate constant for aqueous-phase IEPOX SOA formation catalyzed by $\mathrm{H}^{+}$, $\mathrm{HSO}_{4}^{-}$with water and $\mathrm{SO}_{4}^{2-}$ as nucleophiles.

\begin{tabular}{lll}
\hline Rate constant & Value $\left(\mathrm{M}^{-2} \mathrm{~s}^{-1}\right)$ & Reference \\
\hline$k_{\mathrm{H}^{+}, \text {water }}$ & $9.00 \times 10^{-4}$ & Eddingsaas et al. (2010), Pye et al. (2013) \\
$k_{\mathrm{HSO}_{4}^{-} \text {, water }}$ & $1.31 \times 10^{-5}$ & Eddingsaas et al. (2010) \\
$k_{\mathrm{H}^{+}, \mathrm{SO}_{4}^{2-}}$ & $1.27 \times 10^{-3}$ & Riedel et al. (2016), Budisulistiorini et al. (2017) \\
\hline
\end{tabular}

Table 3. Brief summary of different simulations conducted in this work in CMAQ v5.2.1.

\begin{tabular}{|c|c|}
\hline Simulations & Details \\
\hline NonPhaseSep & $\begin{array}{l}\text { Base CMAQ v5.2.1 parameterization } \\
\text { assuming homogeneous, internally } \\
\text { mixed organic-inorganic fine aerosol, } \\
\text { no phase separation (Pye et al., 2017) }\end{array}$ \\
\hline PhaseSep2 & $\begin{array}{l}\text { Additional term in reactive uptake cal- } \\
\text { culation to capture the impact of phase } \\
\text { separation and organic coating de- } \\
\text { scribed in Sect. } 2.1-2.3 \text { and } 2.5 \text {; Zuend } \\
\text { and Seinfeld (2012) phase-separation } \\
\text { criteria for both liquid and solid or } \\
\text { semi-solid particles (see Sect. } 2.3 \text { ) }\end{array}$ \\
\hline Emissions Reduction & $\begin{array}{l}\text { EPA-recommended emission reduc- } \\
\text { tions for the year } 2025 \text { of } 34 \% \text { and } \\
48 \% \text { for } \mathrm{NO}_{x} \text { and } \mathrm{SO}_{2} \text { from base } 2013 \\
\text { scenario (see Sect. } 2.6)\end{array}$ \\
\hline HighHorg & $\begin{array}{l}\text { Higher organic-phase Henry's law co- } \\
\text { efficient ( } 3 \text { orders of magnitude higher } \\
\text { than in PhaseSep or PhaseSep2) (see } \\
\text { Sect. 2.6) }\end{array}$ \\
\hline PhaseSep & $\begin{array}{l}\text { All parametrization is the same as in } \\
\text { PhaseSep } 2 \text { except for the sensitivity } \\
\text { that Zuend and Seinfeld (2012) phase- } \\
\text { separation criteria are not followed } \\
\text { for solid or semi-solid particles (see } \\
\text { Sect. 2.6) }\end{array}$ \\
\hline
\end{tabular}

\subsection{Phase separation}

Unlike the case of liquid particles, phase-separation frequencies in solid or semi-solid particles are not well understood as stated in Sect. 2.1. We predict LLPS to occur for aerosols with $\eta_{\text {org }} \leq 100$ Pas or $T_{\mathrm{g}, \text { org }}: T<0.8$ (Shiraiwa et al., 2017) and when $\mathrm{RH} \leq$ separation relative humidity (SRH LLPS) (Bertram et al., 2011; You et al., 2014). Song et al. (2018) suggests that LLPS always happens when $(\mathrm{O}: \mathrm{C})_{\mathrm{avg}} \leq 0.56$, which we implemented to predict phase separation. When $(\mathrm{O}: \mathrm{C})_{\text {avg }}>0.56$, phase separation (or rather LLPS) is predicted based on the conditions specified in Eqs. (8) and (9). As a model simplification, solid or semi- solid phase-separated particles (SSPSs) occur following the aforementioned LLPS criteria, but when $\eta_{\text {org }}>100 \mathrm{Pas}$ or $T_{\mathrm{g}, \text { org }}: T \geq 0.8$, to create a broader scenario referred to as PhaseSep2 (see Table 3). The $\mathrm{SRH}_{\text {LLPS }}$ is dependent on OA composition, as shown in Eqs. (8) and (9) based on Bertram et al. (2011), Zuend and Seinfeld (2012) and Song et al. (2018):

$\mathrm{SRH}_{\mathrm{LLPS}}=35.5+339.9(\mathrm{O}: \mathrm{C})_{\mathrm{avg}}-471.8(\mathrm{O}: \mathrm{C})_{\mathrm{avg}}^{2}$,

when $0.56<(\mathrm{O}: \mathrm{C})_{\mathrm{avg}} \leq 0.73$ and

$0.1<(\mathrm{OM}$ : inorganic sulfate $) \leq 15$

$\mathrm{SRH}_{\text {LLPS }}=0$,

when $(\mathrm{O}: \mathrm{C})_{\mathrm{avg}}>0.73$ and

$0.1<(\mathrm{OM}:$ inorganic sulfate $) \leq 15$.

\subsection{Model description and implementation}

All simulations were completed in CMAQ v5.2.1 for the SOAS campaign from 1 June to 15 July 2013, with $10 \mathrm{~d}$ of spin-up time starting on 21 May 2013. Model inputs are described in $\mathrm{Xu}$ et al. (2018). The horizontal resolution of the simulation was $12 \mathrm{~km} \times 12 \mathrm{~km}$. Model vertical extent between the surface and $50 \mathrm{hPa}$ (representing possible stratospheric influences) consisted of 35 layers of variable thickness. The Advanced Research Weather Research and Forecasting model (ARW) version 3.8 with lightning assimilation was used to generate the meteorological inputs for the simulations (Appel et al., 2017; Heath et al., 2016). The National Emission Inventory (NEI) 2011 v2 produced by the EPA was used to generate anthropogenic emissions. Biogenic emissions were determined using the Biogenic Emission Inventory System (BEIS) v3.6.1 (Bash et al., 2016). BEIS predicts lower emissions amounts for isoprene than the Model of Emissions of Gases and Aerosols from Nature (MEGAN) (Carlton and Baker, 2011). Therefore, emissions of isoprene were increased in this work to 1.5 times their original levels based on Pye et al. (2017), who found that this increase led to better agreement with field measurements of isoprene and $\mathrm{OH}$ at the Centreville site during the 2013 SOAS. Carbon Bond v6.3 (CB6r3) was used for the gas-phase chemistry in the model (Emery et al., 2015; Ruiz and Yarwood, 2013; Yarwood et al., 2010). 


\subsection{Reactive uptake}

IEPOX-derived SOA is modeled with a first-order heterogeneous uptake reaction that includes a new term that accounts for diffusion limitations due to an organic coating when the aerosol phase state demands it, as described below in Eqs. (10)-(13) (Anttila et al., 2006; Gaston et al., 2014; Ryder et al., 2014; Budisulistiorini et al., 2017). The impact of organic coating was not considered in the original IEPOX reactive uptake algorithm in CMAQ (Pye et al., 2013):

$\operatorname{IEPOX}_{(\mathrm{g})} \rightarrow$ IEPOXSOA $_{(\text {aerosol })}$.

This first-order heterogeneous-reaction rate constant $\left(k_{\text {het }}\right)$ is defined as

$k_{\text {het }}=\frac{\mathrm{SA}}{\frac{r_{\mathrm{p}}}{D_{\mathrm{g}}}+\frac{4}{\nu \gamma}}$

where SA is the aerosol surface area $\left(\mu \mathrm{m}^{2} \mathrm{~m}^{-3}\right), v$ is the mean molecular speed $\left(\mathrm{m} \mathrm{s}^{-1}\right)$ of gas-phase IEPOX estimated by Eq. (12):

$v=\sqrt{\frac{8 \mathrm{RT}}{\pi \mathrm{MW}_{\mathrm{IEPOX}}}}$

$r_{\mathrm{p}}$ is the effective molecular particle radius including both the inorganic core and organic shell (m), $D_{\mathrm{g}}$ is IEPOX diffusivity in the gas phase $\left(1.9 \cdot\left(\mathrm{MW}_{\text {IEPOX }}\right)^{-\frac{2}{3}} \mathrm{~m}^{2} \mathrm{~s}^{-1}\right), \mathrm{MW}_{\text {IEPOX }}=$ $118 \mathrm{~g} \mathrm{~mol}^{-1}$ is the molecular weight of IEPOX and $\gamma$ is the reactive uptake coefficient:

$$
\begin{aligned}
\frac{1}{\gamma} & =\frac{1}{\alpha}+\frac{v r_{\mathrm{p}}^{2}}{4 H_{\mathrm{inorg}} R T D_{\mathrm{a}} r_{\mathrm{core}}} \frac{1}{q \operatorname{coth}(q)-\frac{1}{q}} \\
& +\frac{v l_{\text {org }} r_{\mathrm{p}}}{4 H_{\mathrm{org}} R T D_{\mathrm{org}, \mathrm{eff}} r_{\mathrm{core}}} .
\end{aligned}
$$

$\alpha$ is the accommodation coefficient (0.02). $H_{\text {inorg }}$ is Henry's law coefficient into the inorganic core $\left(3 \times 10^{7} \mathrm{Matm}^{-1}\right)$. $R$ is the gas constant $\left(0.08206 \mathrm{Latm}^{-1} \mathrm{~K}^{-1} \mathrm{~mol}^{-1}\right)$, and $T$ is the ambient temperature $(\mathrm{K})$.

$D_{\text {a }}$ is the IEPOX diffusivity in the aerosol core $\left(10^{-9} \mathrm{~m}^{2} \mathrm{~s}^{-1}\right)$ and $q$ is the diffuso-reactive parameter as defined in Eq. (14):

$q=r_{\mathrm{p}} \sqrt{\frac{k_{\text {particle }}}{D_{\mathrm{a}}}}$.

$k_{\text {particle }}$ is the pseudo-first-order rate constant $\left(\mathrm{s}^{-1}\right)$ defined in Eq. (15) (Pye et al., 2013), with parameters defined in Table 2:

$k_{\text {particle }}=\sum_{i=1}^{N} \sum_{j=1}^{M} k_{i, j}\left[\operatorname{nuc}_{i}\right]\left[\operatorname{acid}_{j}\right]$.
$D_{\text {org.eff }}\left(\mathrm{m}^{2} \mathrm{~s}^{-1}\right)$ is the effective diffusivity of IEPOX through an organic coating compromised of the species given in Table 1 and $10 \%$ of the total aerosol liquid water.

The contribution of organic species to the volume of the core is assumed negligible and water moves freely between the inorganic core and the organic shell, leading to approximately $90 \%$ aerosol water in inorganic core and $10 \%$ in the organic shell for this work as described by Pye et al. (2017). An extension of this assumption is that the inorganic ion species are concentrated entirely within the aqueous core when calculating $k_{\text {particle }} . H_{\text {org }}\left(2 \times 10^{5} \mathrm{Matm}^{-1}\right)$ is the effective Henry's law constant for the organic coating and $l_{\text {org }}$ is the organic shell thickness given by Eq. (16) calculated at each time step based on Riemer et al. (2009). $r_{\mathrm{p}}$ is the surface-area-weighted median particle radius based on surface area distribution of different species and $\beta$ is the ratio of inorganic particle volume $(90 \%$ of the particle water and inorganic species) to the total particle volume (all organic species, water and inorganic species):

$l_{\text {org }}=r_{\mathrm{p}}\left(1-\beta^{\frac{1}{3}}\right)$,

$r_{\mathrm{p}}$ is the effective aerosol radius $(m)$, the same as in Eqs. (11), (13) and (14), and $r_{\text {core }}$ is the aerosol inorganic core radius $(m) . r_{\text {core }}$ is defined based on Riemer et al. (2009) below:

$r_{\text {core }}=r_{\mathrm{p}} \beta^{\frac{1}{3}}$.

Particles that did not have LLPS or SSPS morphology were assumed to form a homogeneous mixture of organics and inorganics (i.e., $l_{\text {org }}=0$ ), reducing Eq. (13) to the standard CMAQ treatment.

\subsection{Sensitivity simulations}

Three sensitivity simulations were performed, besides the phase state and primary phase-separation prediction mechanism in CMAQ as detailed in Sect. 2.1-2.5 (PhaseSep2; see Table 3). A sensitivity simulation (Emissions Reduction) was conducted using the EPA's emission reductions estimates for the year 2025 of $34 \%$ and $48 \%$ for $\mathrm{NO}_{x}$ and $\mathrm{SO}_{2}$, respectively (Marais et al., 2016; Eyth et al., 2014). A second sensitivity (HighHorg) was conducted that used the same upper bound of $H_{\text {org }}$ as reported by Schmedding et al. (2019) increasing the value from $2 \times 10^{5}$ to $3 \times 10^{8} \mathrm{Matm}^{-1}$. To better understand the effects of viscosity on particle morphology and phase separation, a third sensitivity simulation (PhaseSep) was conducted. In PhaseSep, all particles with $\eta_{\text {org }}>100$ Pa s were assumed to be automatically phase separated with a semi-solid outer core, also referred to as SSPS morphology. While guidelines laid down in Sect. 2.3 (Eqs. 8 and 9 along with phase separation always happening at $\left.(\mathrm{O}: \mathrm{C})_{\mathrm{avg}} \leq 0.56\right)$ are now applicable only for LLPS in PhaseSep. Table 3 gives a brief description of the NonPhaseSep simulation (base CMAQ without phase state and organic coating impacts), the updated PhaseSep2 proposed 
in this work and the three sensitivity simulations: Emissions Reduction, HighHorg and PhaseSep.

\subsection{Measurement comparisons}

Field data were collected using a high-resolution time-offlight chemical ion mass spectrometer (HR-ToF-CIMS) coupled with a filter inlet for gases and aerosols (FIGAERO) and a two-dimensional gas chromatography time-of-flight mass spectrometer $(\mathrm{GC} \times \mathrm{GC}-\mathrm{ToF}-\mathrm{MS})$ at the Centreville, $\mathrm{AL}$, site during the 2013 SOAS campaign (H. Zhang et al., 2018). The combined measurements provide comprehensive and quantitative characterization of particle-phase OA composition with over $800 \mathrm{OA}$ components in these data identified as SOA produced predominantly through VOC oxidation, with a time resolution of $4 \mathrm{~h}$. Chemical formulas were assigned to all the species based on high-resolution peak fitting, and hence their $\mathrm{O}: \mathrm{C}$ ratios and molecular weights were known, which were then used to empirically calculate the average $T_{\mathrm{g}, \text { org }}$ of the OA at the site for the duration of the entire SOAS campaign (1 June-15 July 2013). The speciated OA was estimated to account for $74 \%$ of total fine OA mass during SOAS. The uncharacterized fraction of fine OA (organosulfur compounds, highly oxidized multifunctional molecules (HOMs), etc.) will likely have some influence on the estimated $T_{\mathrm{g}, \text { org }}$. Also note that both techniques use thermal desorption approach to analyze OA composition which was recently shown to cause thermal decomposition for certain species (Lopez-Hilfiker et al., 2016; Cui et al., 2018). Thus, some interferences in $T_{\mathrm{g}, \text { org }}$ estimation could be expected by thermal decomposition; however, at this time, it remains unclear how substantial these interferences could be due to lack of understanding of the degree of decomposition that occurs in these analytical methods. Nevertheless, to our knowledge, this is the most comprehensive molecular-level OA speciation dataset and thus is appropriate to use for comparison with modeled $T_{\mathrm{g}, \text { org }}$ in this work.

We also use observed $\mathrm{O}: \mathrm{C}$ ratios of various HOMs as reported by Massoli et al. (2018) recorded at Centreville forest site, Alabama, during the 2013 SOAS study to compare with the simulations. Massoli et al. (2018) used a high-resolution time-of-flight chemical ionization mass spectrometer with nitrate reagent ion $\left(\mathrm{NO}_{3}^{-} \mathrm{CIMS}\right)$ for these observations. More details are provided in the results section.

Model simulation results (PhaseSep2, HighHorg, Emissions Reduction and PhaseSep) were compared to recorded values for $\mathrm{PM}_{2.5}$ organic carbon mass concentration at monitoring stations that are a part of the South Eastern Aerosol Research Characterization study (SEARCH) (Hansen et al., 2003) to better constrain the parameters used in the calculation of $\gamma_{\text {IEPOX }}$.

\section{Results}

\subsection{Predicted aerosol phase state and phase-separation criteria}

\subsubsection{Predicted phase state at surface}

The ratio of $T_{\mathrm{g}, \text { org }}$ to the ambient $T$ is the strongest indicator of the phase state of the aerosol. The mean, maximum and minimum values for $T_{\mathrm{g}, \text { org }}$ for all grid cells on the surface level and for all time steps were similar for both PhaseSep2 and PhaseSep estimated to be around 207-209, 284-289 and $137 \mathrm{~K}$, respectively. This suggests that particles would be mostly semi-solid or liquid-like because of the similarity to the ambient temperature. The values of $T_{\mathrm{g}, \mathrm{b}}$ and $T_{\mathrm{g}, \mathrm{a}}$ were also the same for both PhaseSep2 and PhaseSep, and ranged from 160 to 301 and 230 to $311 \mathrm{~K}$, respectively. This indicates that anthropogenic species have a narrower range of glass transition temperatures but overall higher values than biogenic species; however, the maximum values of $T_{\mathrm{g}, \mathrm{b}}$ and $T_{\mathrm{g}, \mathrm{a}}$ are more similar than their minimum values. This is attributed to the abundant biogenic acid-catalyzed IEPOX-derived SOA species, such as organosulfates and 2methyltetrols, having a high $T_{\mathrm{g}}$ of $301 \mathrm{~K}$ and a viscosity of $10^{12} \mathrm{Pas}$ as shown in Table 1.

For the simulation period, the diurnal variability (i.e., between day and night) in the ambient $T$ at any site was $\sim 10 \mathrm{~K}$,

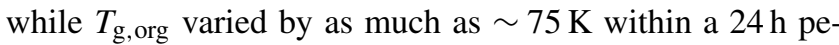
riod. This indicates that changes in the $T_{\mathrm{g}, \text { org }}: T$ ratio (i.e., phase state) were driven by $T_{\mathrm{g} \text {,org }}$ (i.e., composition of the organics and aerosol water in OA) rather than $T$.

\subsubsection{Predicted phase state: vertical distribution}

Figure 1 gives the predicted probability density distribution of the $T_{\mathrm{g}, \text { org }}: T$ ratio for both PhaseSep2 and PhaseSep cases across all grid cells and time steps at different vertical layers of atmosphere: surface, 18th layer (lower troposphere $\sim 1.8 \mathrm{~km}$ above ground level), 28th layer (upper troposphere $\sim 8 \mathrm{~km}$ above ground level) and the 35th layer (lower stratosphere $\sim 17 \mathrm{~km}$ above ground level). At the surface, the PhaseSep simulation has a minimum $T_{\mathrm{g}, \text { org }}: T$ ratio of 0.46 and a maximum of 0.99 , while the corresponding values of the PhaseSep2 simulation were 0.48 and 0.89 , respectively. In the surface layer, over $63.5 \%$ of the $T_{\mathrm{g}, \text { org }}: T$ ratios were less than 0.8 in PhaseSep and $67.0 \%$ for PhaseSep2, a value which is given as the transition point from a semi-solid viscosity to a liquid-like viscosity (Shiraiwa et al., 2017), with the remainder in a solid or semi-solid phase state. PhaseSep as expected has a higher fraction of solid or semi-solid particles, also with higher viscosity than PhaseSep2. In the lower and upper troposphere, the majority of SOA in PhaseSep and PhaseSep2 had $T_{\mathrm{g}, \text { org }}: T$ ratios between 0.8 and 1.0, suggesting semi-solid behavior. Particles in the lower stratosphere 

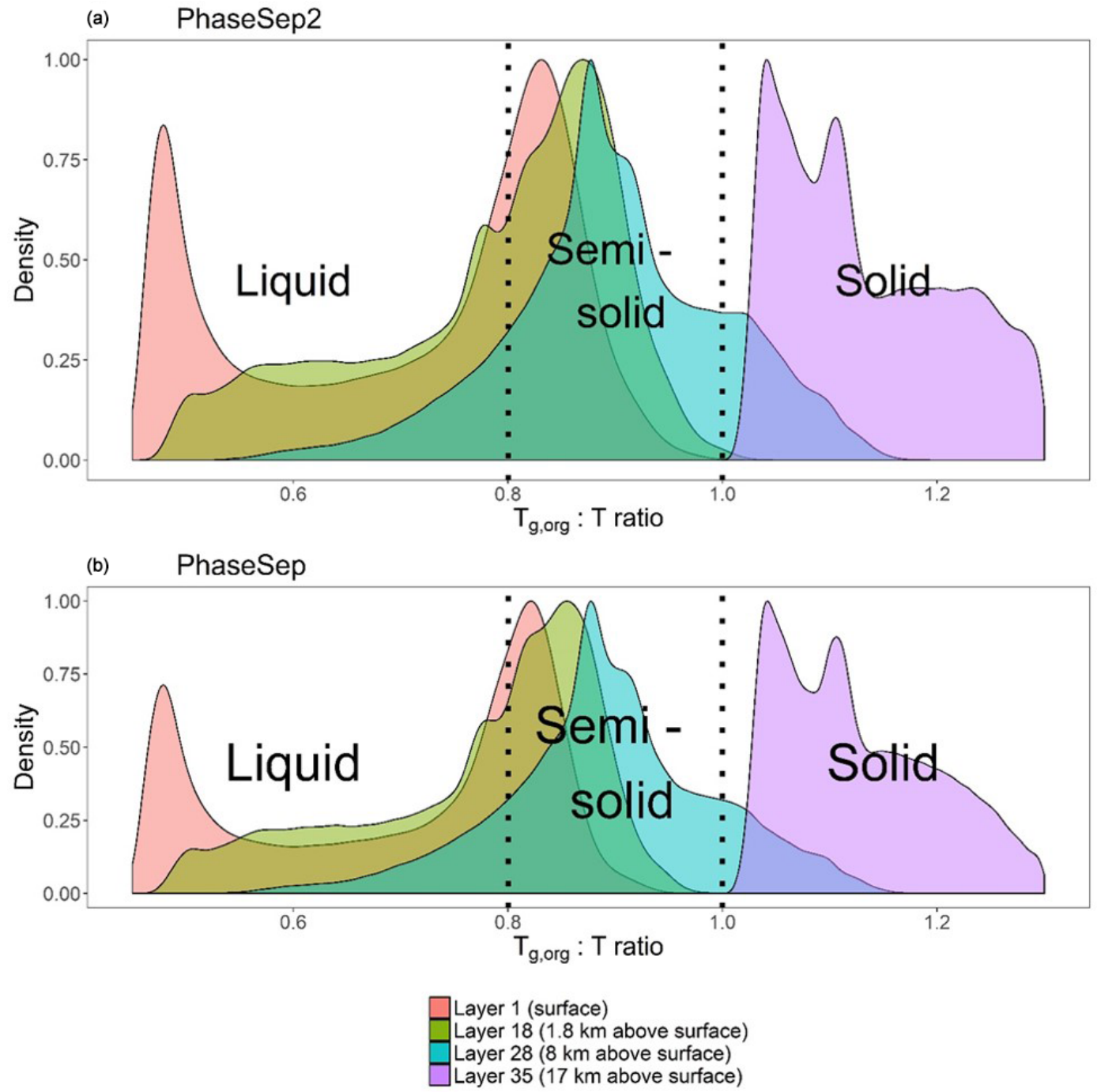

Figure 1. Probability density distribution of glass transition temperature to ambient temperature ratio $\left(T_{\mathrm{g}, \text { org }}: T\right)$ for all grid cells and time steps for (a) the PhaseSep2 simulation and (b) the PhaseSep simulation at the surface layer (red), lower troposphere (green), upper troposphere (blue) and stratosphere (purple).

for both simulations exhibited $T_{\mathrm{g}, \text { org }}: T$ ratios $>1$ that suggested a glassy state.

\subsubsection{Predicted phase state: spatial variability}

Figure 2a shows a map of the average surface layer $T_{\mathrm{g}, \text { org }}: T$ ratio across the continental United States for the duration of the PhaseSep2 simulation. The $T_{\mathrm{g}, \text { org }}: T$ ratios exhibited a bimodal distribution both at the surface and in the lower troposphere (Fig. 1), where particles over the oceans had substantially higher $w_{\mathrm{s}}$. Particles dominated by $w_{\mathrm{s}}$ had $T_{\mathrm{g}, \text { org }}$ similar to $T_{\mathrm{g}, \mathrm{w}}$, with reduced influence from $w_{\mathrm{a}}$ and $w_{\mathrm{b}}$, which decreased their $T_{\mathrm{g}, \mathrm{org}}: T$ ratio as $T_{\mathrm{g}, \mathrm{w}}$ is substantially lower than the predicted $T_{\mathrm{g}}$ values for organic species. These particles correspond to the peak at $T_{\mathrm{g}, \text { org }}: T$ at over approximately 0.5 (Fig. 1). Semi-solid particles with a higher range of $T_{\mathrm{g}}$ values (Fig. 2a) were concentrated over areas associated with higher anthropogenic SOA (including anthropogenic POA listed in Table 1) and a low RH, aerosol liquid water content and biogenic SOA, such as the American southwest and Rocky Mountains. These higher $T_{\mathrm{g}}$ values pulled the overall $T_{\mathrm{g} \text {,org }}$ value up closer to the ambient temperature and thus brought the $T_{\mathrm{g}, \text { org }}: T$ ratio closer to 1 , which is shown in the cluster of peaks between $T_{\mathrm{g}, \text { org }}: T=$ 0.8 and $T_{\mathrm{g}, \text { org }}: T=1$.

Figure $2 \mathrm{~b}, \mathrm{c}$ and $\mathrm{d}$ show the spatial profiles of the mean $T_{\mathrm{g}, \text { org }}: T$ ratio for each grid cell at the 18th layer of CMAQ (lower troposphere), 28th layer of CMAQ (upper troposphere) and the 35th layer of CMAQ (stratosphere). The value of $T$ drops with the decreasing pressure. The $\mathrm{O}: \mathrm{C}$ ratio of the particles are predicted to increase when compared 


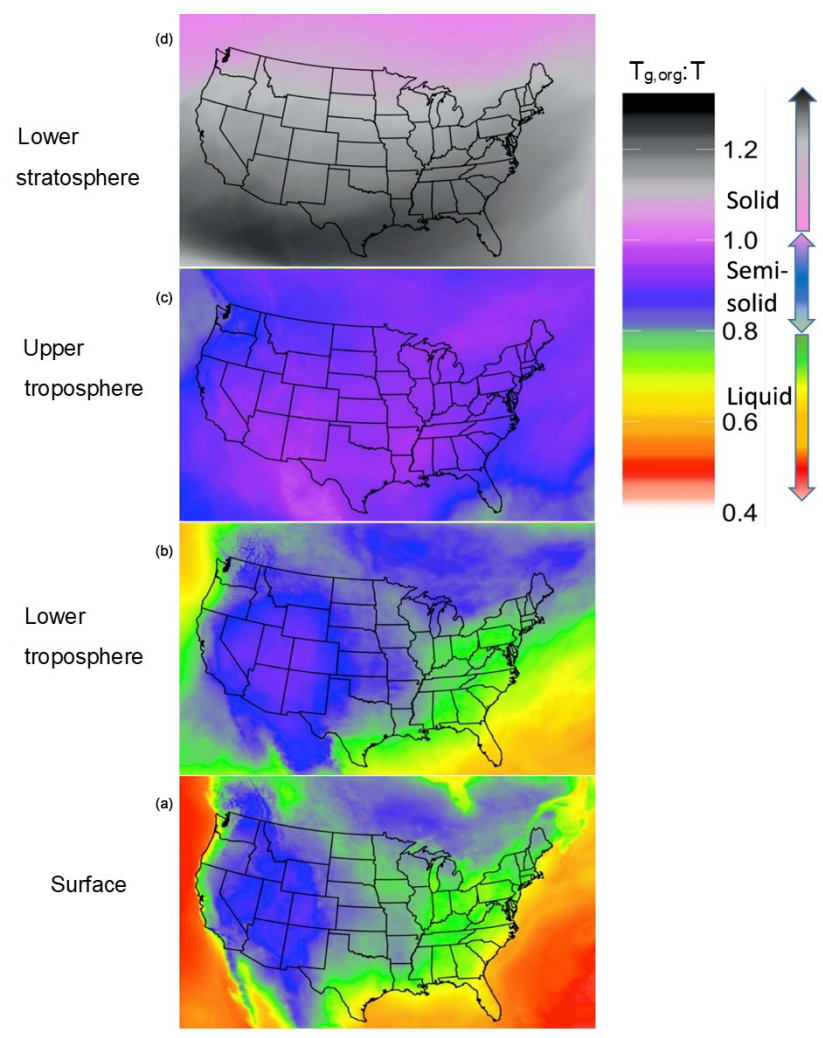

Figure 2. For all time steps and over the continental United States, the average glass transition temperature to ambient temperature ( $T_{\mathrm{g}, \text { org }}: T$ ) ratio at (a) the surface level, (b) $1.8 \mathrm{~km}$ above the surface layer (lower troposphere), (c) $8 \mathrm{~km}$ above the surface layer (upper troposphere) and (d) $17 \mathrm{~km}$ above the surface layer (stratosphere) for the PhaseSep2 simulation.

to the surface due to atmospheric oxidation. The mean $\mathrm{O}: \mathrm{C}$ ratio of all particles at the surface was 0.73 , while across the troposphere (at layers 18 and 28) it increased slightly to 0.75 , and at layer 35 it was 0.77 . The PhaseSep2 simulation followed a similar pattern of increasing $\mathrm{O}: \mathrm{C}$ ratios as PhaseSep but starting higher at surface $\sim 0.75$ and increasing to 0.79 at layer 35 . Species with high $\mathrm{O}: \mathrm{C}(>$ 1.6) parameterized in CMAQ as anthropogenic OA collectively can be used as a surrogate for highly oxygenated organic aerosol (OOA), specifically low-volatility oxygenated organic aerosol (LVOOA) and semi-volatile oxygenated organic aerosol (SVOOA). Table 1 shows the species that led to this specific modeled change in $\mathrm{O}: \mathrm{C}$ with elevation. The mean mass fraction of anthropogenic OA increased from $\sim 40 \%$ at surface to $\sim 65 \%$ at the upper troposphere and eventually $\sim 80 \%$ at layer 35 in both PhaseSep and PhaseSep2, whereas biogenic OA composed of isoprene-derived OA drops from $\sim 30 \%$ at surface to $24 \%$ at the upper troposphere and eventually $\sim 20 \%$ at layer 35 . The higher O : C in PhaseSep2 relative to PhaseSep is connected to higher biogenic OA as well (Fig. 4c and e). This is in agreement with the findings from airborne measurements in the southeastern
United States as part of the Southeast Nexus (SENEX) field campaign that show a sharp drop in isoprene-derived OA and drastic increase in OOA with rising altitude (Xu et al., 2016). The mean value of $T_{\mathrm{g} \text {,org }}$ also increased from $207 \mathrm{~K}$ at the surface to $219 \mathrm{~K}$ at layer $18,223.5 \mathrm{~K}$ at layer 28 and $239 \mathrm{~K}$ at layer 35 . This change in $T_{\mathrm{g} \text {,org }}$ was primarily driven by decreases in organic water in the aerosol, which decreased from an average $29 \%$ at the surface to $1.4 \%$ at layer 35 . The removal of water from the organic phase led to the disappearance of the bimodal $T_{\mathrm{g}, \text { org }}: T$ ratio beyond the 28th layer (upper troposphere).

The mean $T_{\mathrm{g}, \text { org }}: T$ ratio was less than 1 in the lower troposphere for PhaseSep and PhaseSep2. PhaseSep predicted $59.7 \%$ of particles were likely to be liquid based on the $T_{\mathrm{g}, \text { org }}: T$ ratio $<0.8$, while PhaseSep2 predicted that $45.4 \%$ would likely be liquid-like. The remaining semi-solid particles were still concentrated over the American southwest and Rocky Mountains. The difference between $T_{\mathrm{g}, \text { org }}: T$ ratio was more pronounced in the upper troposphere, where PhaseSep predicted $69.4 \%$ of particles would have semi-solid behavior, with the remainder almost evenly split between liquid-like and glassy behavior. On the other hand, PhaseSep2 predicted over $99.6 \%$ of particles in the upper troposphere would be semi-solid. At the 35th layer of CMAQ, all particles in both simulations had a $T_{\mathrm{g}, \text { org }}: T$ ratio $>1$, indicating glassy viscosities. Particles with the highest $T_{\mathrm{g}, \text { org }}: T$ ratio at this altitude were located over the southern half of the simulation area, with $T_{\mathrm{g}, \text { org }}: T$ ratios approaching $\sim 1$ in the northern half of the simulation. Particles in the northern half of the continental United States domain had higher concentrations of biogenic and anthropogenic SOA in comparison to those in the southern half of the domain and therefore had

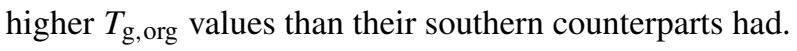

\subsubsection{Phase-separation frequency with different phase-separation criteria}

Whether a particle is semi-solid or liquid, and whether it has LLPS or SSPS morphology, is influenced by the proportions of SOA constituents, including water. The overall phase-separation frequency using the PhaseSep criteria was $68.5 \%$, where $54.8 \%$ of predicted viscosities were greater than $100 \mathrm{Pas}$, indicating that they exhibited SSPS morphology. The median viscosity of SSPS particles was on the order of $10^{3} \mathrm{Pas}$, just above the threshold where particles start exhibiting a glassy state. The remaining $13.7 \%$ of the phaseseparated particles exhibited a LLPS morphology. The median viscosity of LLPS particles was on the order of $10^{\circ} \mathrm{Pas}$, indicating a very liquid-like state. $D_{\text {org,eff }}$, which is inversely related to $\eta_{\text {org }}$ as derived from Eq. (1), had a mean and median of $3.40 \times 10^{-12}$ and $3.94 \times 10^{-11} \mathrm{~m}^{2} \mathrm{~s}^{-1}$, respectively. The mean $\mathrm{O}: \mathrm{C}$ ratio of LLPS particles was 0.68 . The mean values of $w_{\mathrm{a}}$ and $w_{\mathrm{b}}$ in LLPS were $37.7 \%$ and $19.8 \%$. The largest observed contributions of $w_{\mathrm{a}}$ and $w_{\mathrm{b}}$ to the total organic mass were $96.9 \%$ and $82.1 \%$. This suggests that 
anthropogenic aerosol components are more dominant than the biogenic components, whereas biogenic components are likely more water soluble with their average $\mathrm{O}$ : $\mathrm{C}$ being 0.72 compared to 0.59 for anthropogenic constituents (Table 1). The mean fraction of the organic shell composed of water $\left(w_{\mathrm{s}}\right)$ was $42.4 \%$ and a maximum of $99.9 \%$.

The removal of the hypothetical assumption that all particles with a semi-solid viscosity were phase separated (PhaseSep2) decreased the overall phase-separation frequency to $29 \%$ from $68.5 \%$ in the PhaseSep simulation. The entirety of this reduction was from reductions in SSPS only. The phase-separation frequency at the Centreville, Alabama, site decreased to $65.4 \%$ from $79.3 \%$, which is still in agreement with the values reported by Pye et al. (2017).

\subsubsection{Diurnal influence of $\mathrm{OA}$ composition on phase state}

Figure 3 shows the diurnal profile of model extracted $T_{\mathrm{g} \text {,org }}$ and relative contributions of the model-predicted anthropogenic, biogenic and water fractions to $T_{\mathrm{g} \text {, org }}$ for 1 June15 July 2013 at two SEARCH monitoring sites: a rural site in Centreville, Alabama (Fig. 3a and c), and at an urban site at the Jefferson Street, Atlanta, Georgia (Fig. 3b and d). These diurnal profiles are pretty much same for both PhaseSep2 and PhaseSep cases. Both the Centreville and Atlanta sites (Fig. 3) had $T_{\text {g, org values that ranged } \sim 150-250 \mathrm{~K}}$ (Fig. 3). The rural Centreville site is dominated by biogenic OA (Fig. 3c), whose diurnal trend is similar to that of overall $T_{\mathrm{g}, \text { org }}$ at this site (Fig. 3a), whereas the Jefferson Street site has a significant presence of both anthropogenic and biogenic OA, but the diurnal trend of $T_{\mathrm{g} \text {, org }}$ at this site (Fig. $3 \mathrm{~b}$ ) is similar to anthropogenic OA which dominates slightly (Fig. 3d). Figure 3 also gives the diurnal pattern of relative contribution of aerosol liquid water (associated with organics) to $T_{\mathrm{g} \text {, org }}$. The peaks in $T_{\mathrm{g} \text {, org }}$ coincided with the daytime period of high emissions of VOCs and lower contribution of aerosol liquid water (Fig. 3). At night and in the early morning, due to higher contribution of aerosol liquid water, $T_{\mathrm{g} \text {, org }}$ is lower than in daytime for both the sites (Fig. 3). $T_{\mathrm{g} \text {, org }}$ at the urban Jefferson Street site (Fig. 3b) also shows a sharper contrast between day and night compared to rural Centerville site (Fig. 3a), due to the more pronounced diurnal variations in aerosol liquid water (Fig. 3d). Both sites have a relatively high contribution of aerosol water (generally true for eastern United States; see Fig. 2a) to the organic phase, especially at night and in the early morning for 18:00-08:00 LT (Fig. 3).

\subsubsection{Predicted viscosity}

Figure $4 \mathrm{a}$ gives the probability density distribution of $\eta_{\text {org }}$ at the surface level for all grid cells and time steps for both the PhaseSep and PhaseSep2 simulations. Both simulations predicted a bimodal distribution of $\eta_{\text {org }}$ with comparable median values. Semi-solid and glassy particles tended to have slightly higher viscosities in PhaseSep2 comparison to comparable particles in PhaseSep. Due to large differences in the mean and median of the predicted $\eta_{\text {org }}$ in both simulations, we chose to use the median value as a more robust measure of the central tendency of the predicted $\eta_{\text {org }}$ for interand intra-simulation comparisons. Figure $4 \mathrm{~b}-\mathrm{f}$ show the impacts of different external and internal factors on $\eta_{\text {org }} \mathrm{RH}$ was more strongly correlated with $\eta_{\text {org }}(r=0.68)$ than $\mathrm{O}: \mathrm{C}$ ratio $(r=0.62)$, which was very weakly correlated with viscosity (Fig. 4b-c), The abundance of water relative to organics (Fig. 4f) drives the variability in viscosity and phase separation. Figure $4 \mathrm{~d}-\mathrm{f}$ show that $w_{\mathrm{s}}$ (i.e., water related to organic shell) had the strongest correlation with $\eta_{\text {org }}(r=0.79)$, followed by $w_{\mathrm{b}}(r=0.75)$ and $w_{\mathrm{a}}(r=0.63)$.

\subsubsection{Comparison to observed data}

Figure 5 shows the $T_{\mathrm{g}, \text { org }}: T$ ratio calculated from speciated organic aerosol composition field data at the Centreville, Alabama, field site at $32.944^{\circ} \mathrm{N}, 87.1386^{\circ} \mathrm{W}$ (H. Zhang et al., 2018 ), during the 2013 SOAS period. $T_{\mathrm{g}, \text { org }}: T$ ratio derived from data collected by $\mathrm{H}$. Zhang et al. (2018) ranged from $\sim 0.63$ to 0.88 . Meanwhile, the predicted $T_{\mathrm{g}, \text { org }}: T$ ratios using both PhaseSep 2 and PhaseSep ranged $\sim 0.47$ to 0.88 , slightly exceeding the range predicted from observations. It should be noted that the $\mathrm{H}$. Zhang et al. (2018) observations were recorded every $4 \mathrm{~h}$ for $\sim 60 \%$ of the 2013 SOAS time period. Modeled $T_{\mathrm{g} \text {,org }}: T$ mostly captures the peaks and drops, which the field-observation-derived $T_{\mathrm{g}, \text { org }}: T$ shows (Fig. 5). Some mismatch can be attributed to the lack of an explicit mechanism to compute organic aerosol water uptake in CMAQ and some unaccounted SOA formation mechanisms. Further, H. Zhang et al. (2018) only accounted for $\sim 70 \%$ of SOA species listed in Table 1 . The mean $T_{\mathrm{g} \text {, org }}: T$ ratio predicted from the 2013 SOAS Centerville site field observations was 0.79 compared quite close to the corresponding value of $\sim 0.73$ predicted by both PhaseSep 2 and PhaseSep simulations in CMAQ. The model-estimated $T_{\mathrm{g}, \text { org }}$ : $T$ (both PhaseSep2 and PhaseSep) compared to $T_{\mathrm{g} \text {, org }}: T$ range based on field observations at Centreville, $\mathrm{AL}$, for the 2013 SOAS gives a correlation coefficient of $\sim 0.64$ between them. There is also a discernable consistent diurnal trend across the 2013 SOAS period for $T_{\mathrm{g}, \text { org }}: T$ (Fig. 5), such as stronger contribution of aerosol liquid water for 18:00 08:00 LT and a lowering of the $T_{\mathrm{g} \text {,org }}: T$ during those hours (Fig. 3a and c).

Massoli et al. (2018) reported the observed O : C at the Centreville, AL, site during the 2013 SOAS that ranged between $\sim 0.5$ and 1.4 and averaged 0.91. Massoli et al. (2018) presents the first instance of ambient measurements with a $\mathrm{NO}_{3}^{-}$CIMS in an isoprene-dominated environment and identified organic nitrates or organonitrates (ONs) originating from both isoprene and monoterpene to be a significant component of the $\mathrm{NO}_{3}^{-}$CIMS spectra and dominating the observed SOA at the Centreville site throughout 
(a)

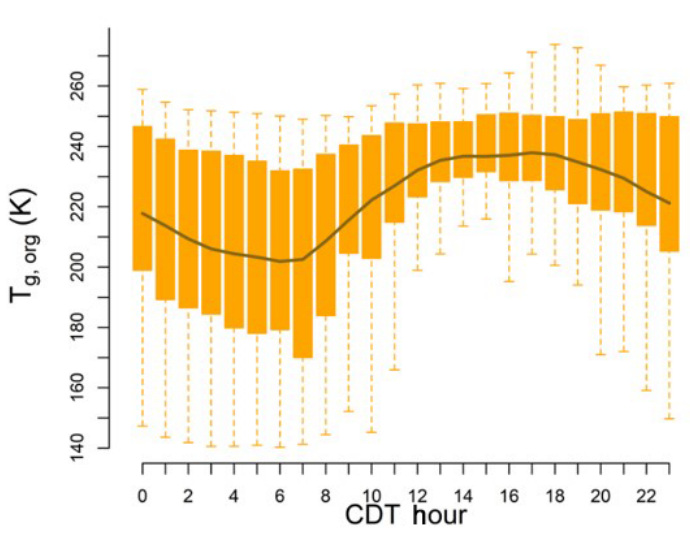

(b)
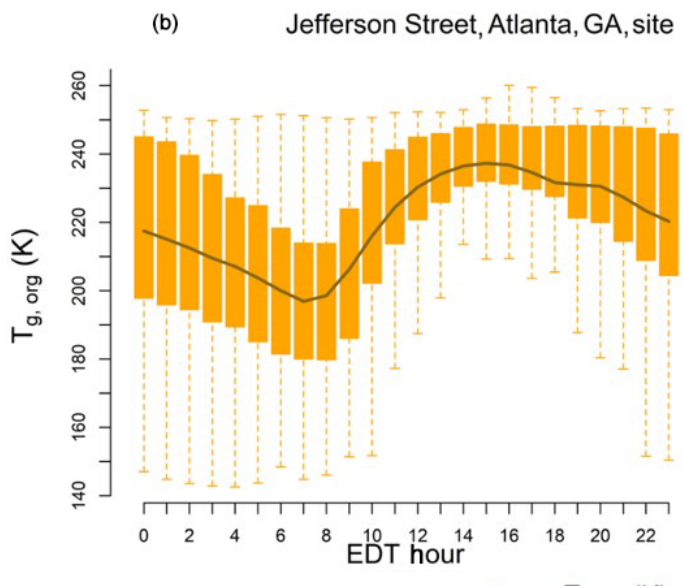

(c)

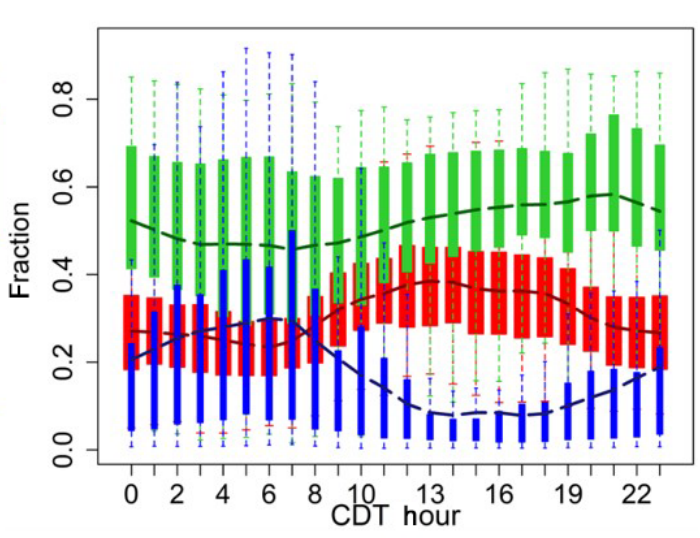

(d) Jefferson Street, Atlanta, GA, site

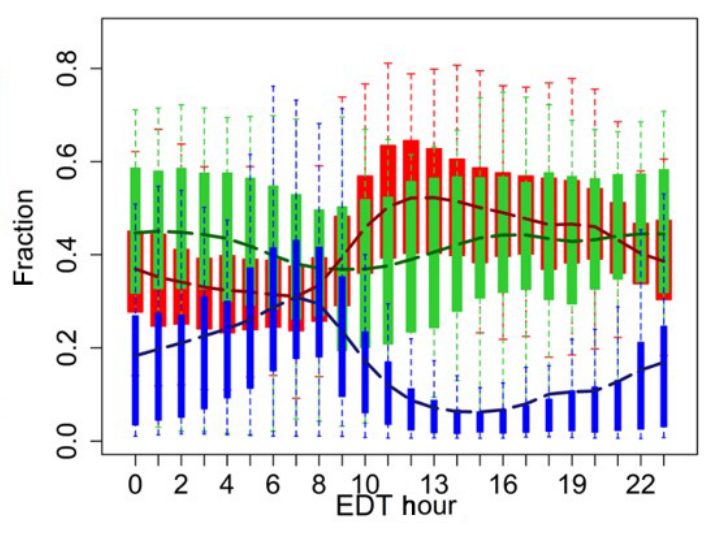

$$
\begin{aligned}
& =T_{g, \text { org }}(\mathrm{K}) \\
& =\quad \text { Anthropogenic } \\
& =\quad \text { Biogenic } \\
& =\quad \text { Aerosol water associated with organics }
\end{aligned}
$$

Figure 3. Diurnal pattern for SOAS (1 June-15 July) 2013 of the organic glass transition temperature ( $T_{\mathrm{g} \text {, org }}-$ orange), and contributions of anthropogenic OA (red), biogenic OA (green) and aerosol water associated with organics (blue) to $T_{\mathrm{g}, \text { org }}$ in the PhaseSep2 case at the (a, c) Centreville, AL, site and the (b, d) Jefferson Street, Atlanta, GA, site. Bars/shaded boxes indicate 25th to 75th percentiles. Extreme bounds of whiskers indicate 5 th to 95 th percentiles (i.e., $95 \%$ confidence interval), and the line indicates the mean.

the day, reflecting daytime and nighttime formation pathways. Both isoprene- and monoterpene-derived ONs have very high $\mathrm{O}: \mathrm{C}(>1)$ and account for up to $10 \%$ of total oxygen at the Centreville site (Xu et al., 2015; B. H. Lee et al., 2016), explaining the high overall observed average $\mathrm{O}: \mathrm{C}$. Our modeled $\mathrm{O}: \mathrm{C}$ at the Centerville, AL, site during the 2013 SOAS ranged between $\sim 0.5$ and 1 and averaged $\sim 0.7$ for both PhaseSep2 and PhaseSep. CMAQ v5.2.1 with carbon bond chemistry (used in this study) uses aero6 aerosol mechanism, without any explicit representation of formation pathways of isoprene- and monoterpenederived ONs. Specifically CMAQ with aero6 significantly underestimates monoterpene oxidation that accounts for $\sim$
$50 \%$ of organic aerosol in the southeastern United States in summer (H. Zhang et al., 2018). Consideration of explicit monoterpene organic nitrates and updated monoterpene photo-oxidation yields in aero7 eliminates the CMAQ model-measurement bias (Xu et al., 2018). The lack of explicit organic nitrates here can explain the lack of high $\mathrm{O}: \mathrm{C}$ (>1) predictions at the Centreville, AL, site during the 2013 SOAS leading to the low correlation of model-estimated $T_{\mathrm{g}, \text { org }}: T$ with observations.

Figure 6 shows the predicted viscosity of our phaseseparation implementation for all days, grid cells and layers sorted into $10 \% \mathrm{RH}$ bins. The trends in range of modeled $\eta_{\text {org }}$ are the same as those in Fig. 4b, with higher mean 

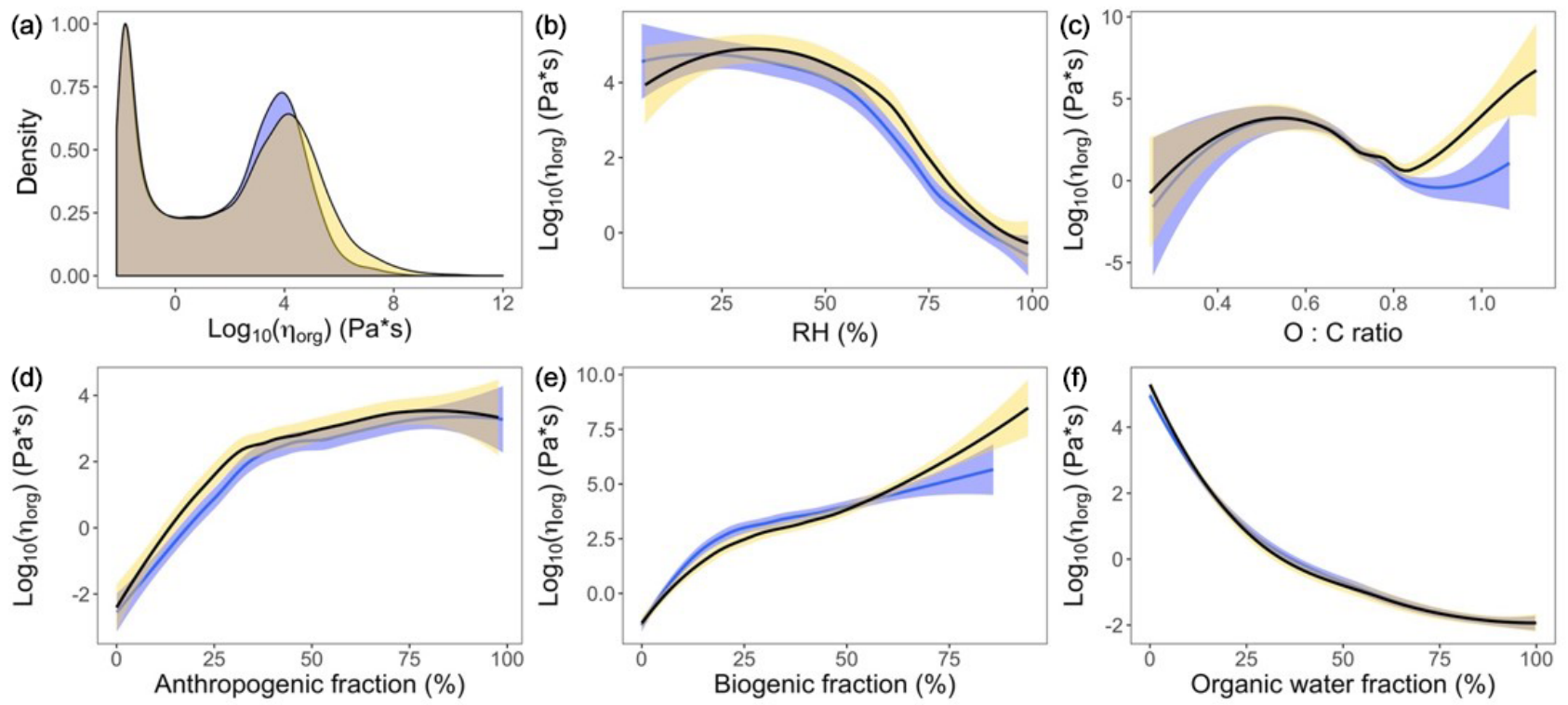

PhaseSep

PhaseSep2

Figure 4. For all grid cells and time steps at the surface layer, the (a) probability distribution of the organic-phase viscosity and correlations of particle viscosity ( $\eta_{\text {org }}$ ) with (b) relative humidity, (c) atomic oxygen to carbon $(\mathrm{O}: \mathrm{C})$ ratio, (d) anthropogenic SOA weight fraction, (e) biogenic SOA weight fraction and (f) organic-phase water content ( $\left.w_{\mathrm{S}}\right)$ for PhaseSep (blue) and PhaseSep2 (gold).

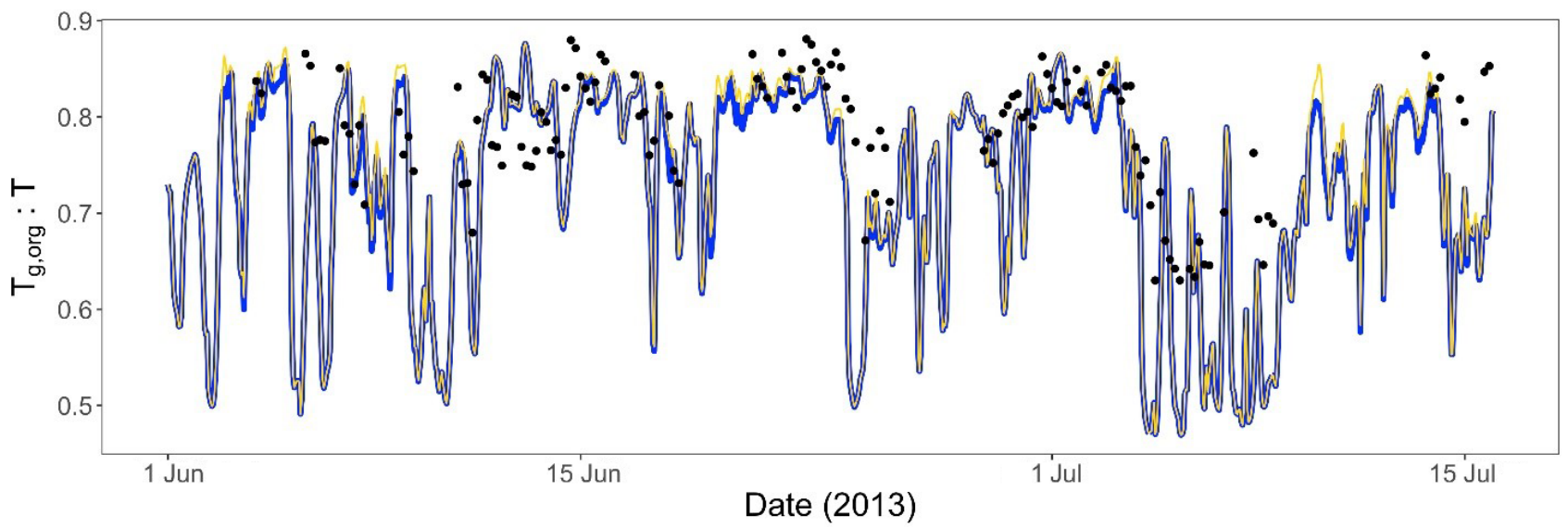

Figure 5. Predicted glass transition temperature to ambient temperature ratio $\left(T_{\mathrm{g}, \text { org }}: T\right)$ at the Centreville, AL, site during the $2013 \mathrm{SOAS}$

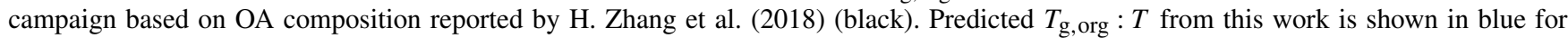
PhaseSep and gold for PhaseSep2.

and quantiles of $\eta_{\text {org }}$ corresponding to lower $\mathrm{RH}$, and vice versa for higher RH. Also shown in Fig. 6 are viscosities of aerosols made in the laboratory. The red dots represent the viscosities of $\alpha$-pinene SOA measured by Y. Zhang et al. (2018), and the blue box plots represent the range of viscosities of toluene SOA measured by Song et al. (2016). Both laboratory-based experimental studies show good agreement at atmospherically relevant $\mathrm{RH}$ ranges with the viscosities predicted by our implementation. At lower RH ranges ( $\sim$ $30 \%$ ), the experimentally measured viscosities are slightly higher than those predicted by our study. This could be attributed to shattering of highly viscous SOA $\left(\eta_{\text {org }} \geq 10^{6} \mathrm{Pas}\right)$ for $\mathrm{RH} \leq 30 \%$ that inhibits their flow in laboratory measurements of $\eta_{\text {org }}$ (Renbaum-Wolff et al., 2013; Zhang et al., 2015; Y. Zhang et al., 2018). Huang et al. (2018) speculates that differences in physicochemical properties of $\alpha$ pinene SOA, including viscosity, can exhibit a "memory effect" of the conditions under which the particle formed. This is regardless of the subsequent conditions to which the particle is exposed. This could lead to differences between 


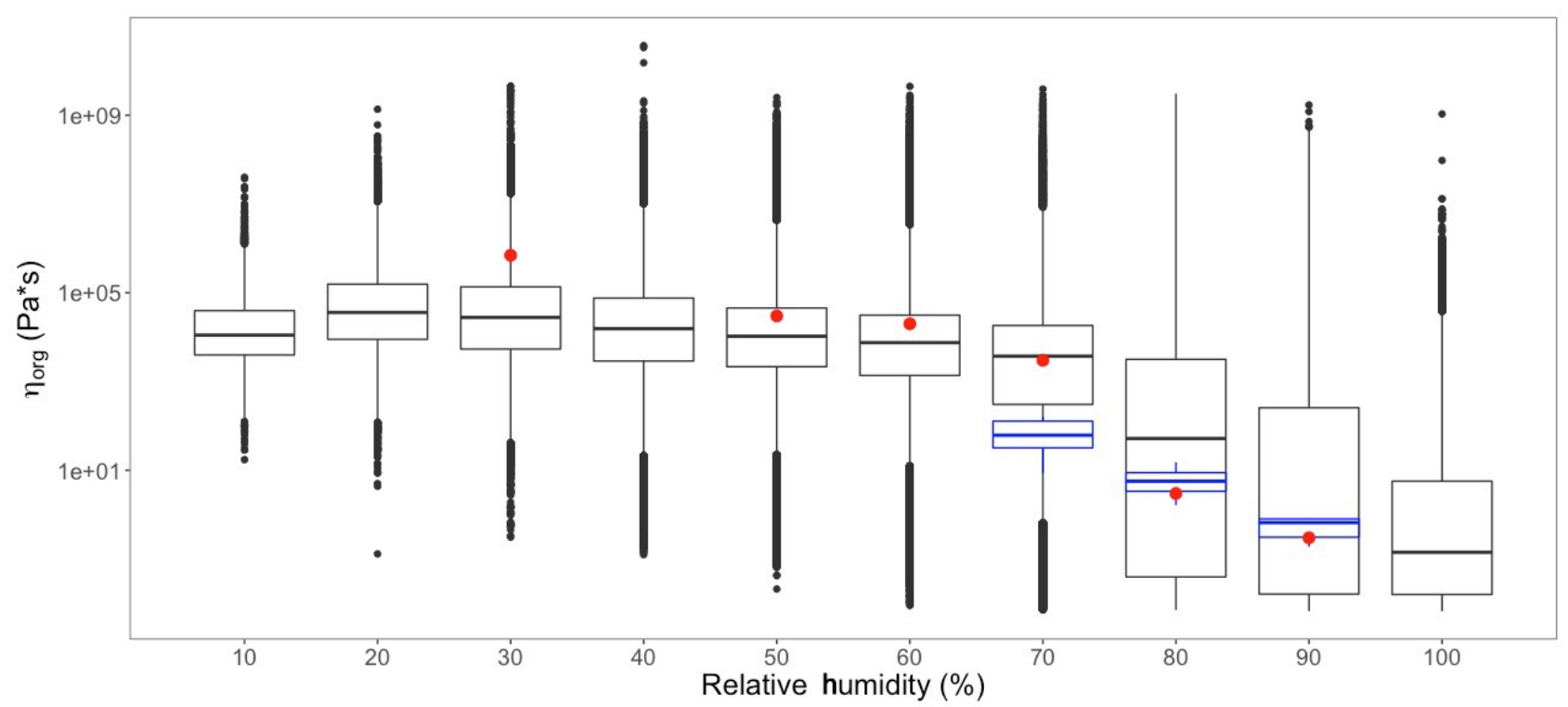

Figure 6. Model-predicted SOA viscosity $\left(\eta_{\text {org }}\right)$ and experimental data for $\eta_{\text {org }}$ from Y. Zhang et al. (2018) (red) and Song et al. (2016) (blue) at varying RH.

model-predicted and experimentally measured viscosities, as these memory effects are not well characterized. Grayson et al. (2016) reports that the viscosity of $\alpha$-pinene SOA may vary as a function of the mass loading conditions with higher mass loading leading to lower viscosity measurements. Unfortunately, there is also a lack of experimental data on viscosity measurements at $\mathrm{RH}<60 \%$.

\subsection{Impact on model predictions}

\subsubsection{Reactive uptake coefficient of IEPOX $\left(\gamma_{\text {IEPOX }}\right)$}

Previous experimental studies show that phase separation forming semi-solid organic aerosol coatings is expected to decrease IEPOX reactive uptake $\left(\gamma_{\text {IEPOX }}\right)$ and thus the resulting SOA (Y. Zhang et al., 2018). Figure 7 clearly is in agreement with Y. Zhang et al. (2018), showing reductions in $\gamma_{\text {IEPOX }}$ with PhaseSep, and PhaseSep2 simulations relative to the NonPhaseSep. Compared to the original CMAQ with no phase separation considered (NonPhaseSep), PhaseSep had a $\sim 18 \%$ decrease for mean $\gamma_{\text {IEPOX }}$ at the surface level, while PhaseSep2 led to a reduction of only $\sim 2 \%$ (Fig. 7a). For the southeastern United States, a similar overall shift of higher $\gamma_{\text {IEPOX values }}>10^{-3}$ in NonPhaseSep to lower values ranging between $10^{-4}$ to $10^{-6}$ occurs with the introduction of phase separation and phase state parameters in CMAQ, much more in PhaseSep than in PhaseSep2 (Fig. S1 in the Supplement).

Across the continental United States, for different locations as well, there is a significant reduction in mean $\gamma_{\text {IEPOX }}$ for the 2013 SOAS period in PhaseSep compared to NonPhaseSep (Fig. 7b and c); however, it is much more simi- lar between PhaseSep2 and NonPhaseSep (Fig. 7b and d). There was high variability in the value of $\gamma_{\text {IEPOX }}$ between regions: specifically, between the eastern and western United States. To understand the drivers that influence changes in $\gamma_{\text {IEPOX }}$ with the new PhaseSep2 and PhaseSep simulations, grid cells that exhibited the maximum increase and decrease relative to the NonPhaseSep were analyzed. When phase separation was included, particles in grid cells and time steps with the maximum reduction in $\gamma_{\text {IEPOX }}$ were the result of a low $D_{\text {org,eff }}$ of $5.83 \times 10^{-19} \mathrm{~m}^{2} \mathrm{~s}^{-1}$ and an $l_{\text {org }}$ as high as $100 \mathrm{~nm}$, i.e., thick organic coating with diffusion limitations. Particles in the grid cell and time step with the highest in-

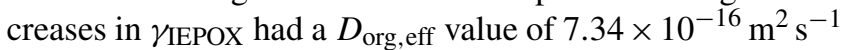
and $l_{\text {org }}$ of $0.67 \mathrm{~nm}$, and were located over oceans with an abundant amount of aerosol liquid water that were in close proximity to biogenic isoprene emission sources (Fig. S2). These large increases in $\gamma_{\text {IEPOX }}$ were primarily caused by increases in $k_{\text {particle }}$ due to added nucleophiles (i.e., abundant aerosol liquid water) and a lack of diffusive limitations through the organic shell. Regions with highest reductions in mean $\gamma_{\text {IEPOX }}$ for the 2013 SOAS period across the continental United States in PhaseSep (southwestern US and southern Canada; Fig. 7c) and PhaseSep2 (midwestern US; Fig. 7d) relative to NonPhaseSep (Fig. 7b) also had higher $l_{\text {org }}$ (Fig. S2). To summarize, the phase (which influences $\left.D_{\text {org,eff }}\right)$ and thickness $\left(l_{\text {org }}\right)$ of the organic coating are the main drivers of change in $\gamma_{\text {IEPOX }}$.

A recent study by Riva et al. (2019) demonstrated that the formation of organosulfates during the IEPOX reactive uptake process leads to an organic coating and thus a reduced $\gamma_{\text {IEPOX }}$. This manifests as a self-limiting effect during the IEPOX-derived SOA formation. Atmospheric models, in- 


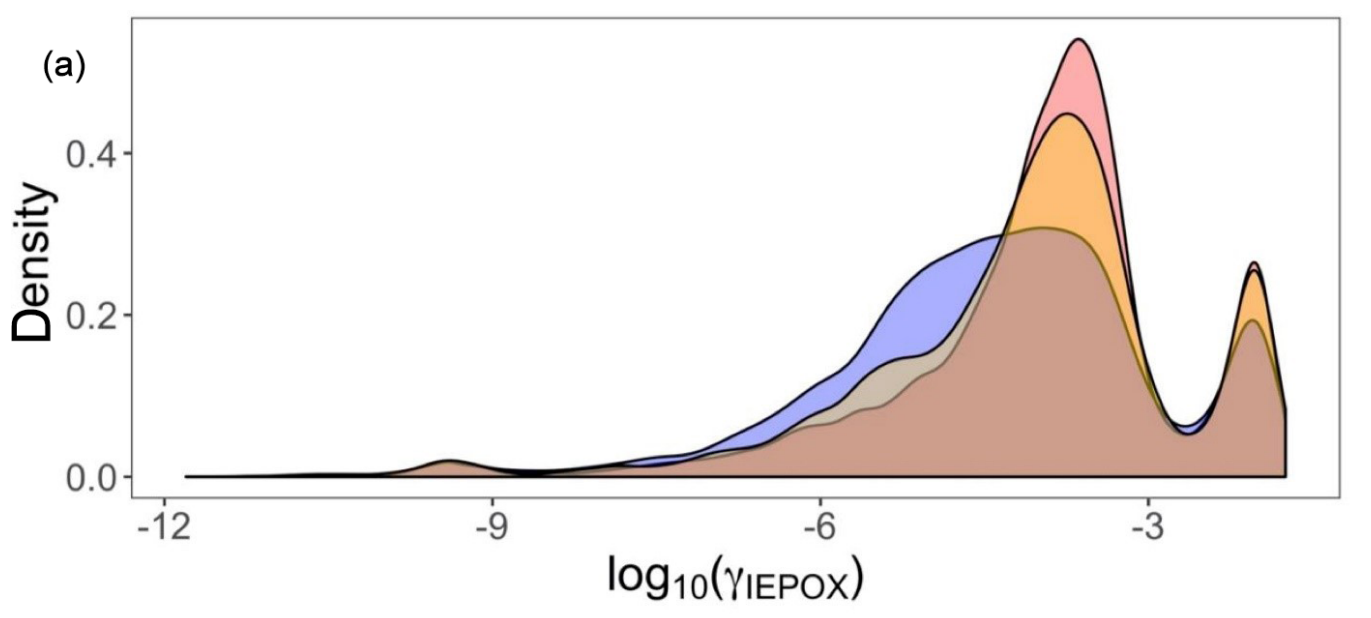

NonPhaseSep $\square$ PhaseSep $\square$ PhaseSep2

(b)

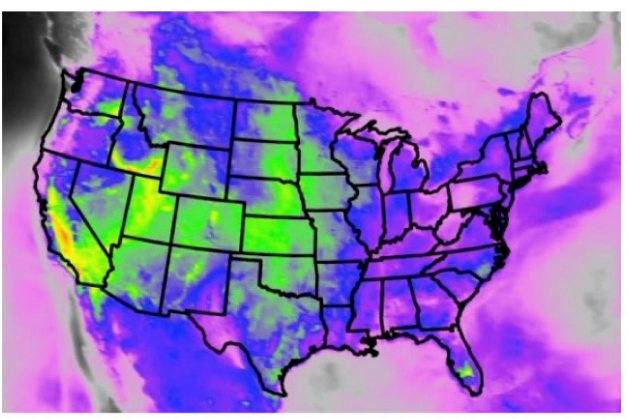

(d)

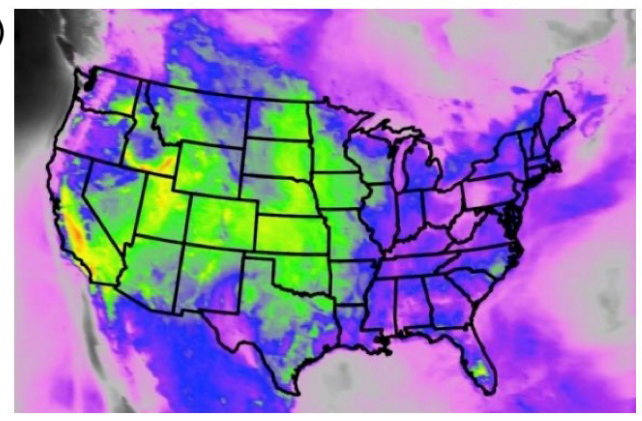

(c)

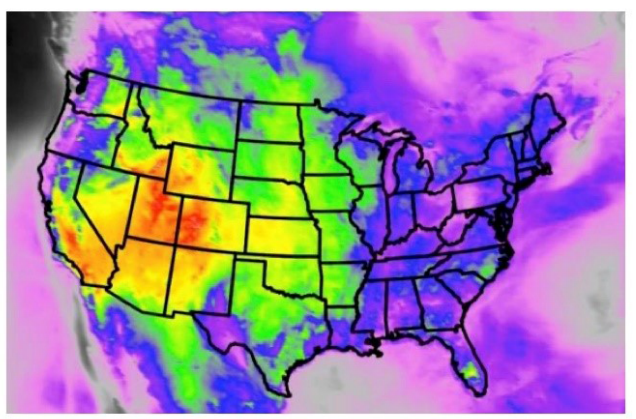

Figure 7. For all grid cells and time steps, the predicted (a) probability distribution of $\gamma_{\text {IEPOX }}$ at the surface level for the NonPhaseSep (red), PhaseSep (blue) and PhaseSep2 (gold) simulations. For each grid cell, the mean value of $\gamma_{\text {IEPOX }}$ for the (b) NonPhaseSep, (c) PhaseSep and (d) PhaseSep2 simulations.

cluding this work, do not consider this recently observed self-limiting process yet, but accounting for it may lead to a further reduction of the $\gamma_{\text {IEPOX }}$. It is also interesting to note that the spatial maximum of mean organic coating thickness across the continental United States for PhaseSep2 and PhaseSep cases came around the thin $(\sim 20 \mathrm{~nm})$ and thick $(\sim 40 \mathrm{~nm})$ organic coating as used in Riva et al. (2019), respectively (Fig. S2).

\subsubsection{Predicted SOA mass}

Variability in $\gamma_{\text {IEPOX }}$, in the PhaseSep2 and PhaseSep relative to the NonPhaseSep (Fig. 7), was also reflected in the large geospatial variations in the concentrations of IEPOXderived SOA, i.e., organosulfates and tetrols (Fig. 8). Higher reductions in the IEPOX-derived SOA for PhaseSep relative to NonPhaseSep were also in regions such as the southwestern United States and southern Canada (more pronounced near the Great Lakes), with higher reductions in $\gamma_{\text {IEPOX }}$ due to thick organic coatings (Fig. S2). Although the southwest- 


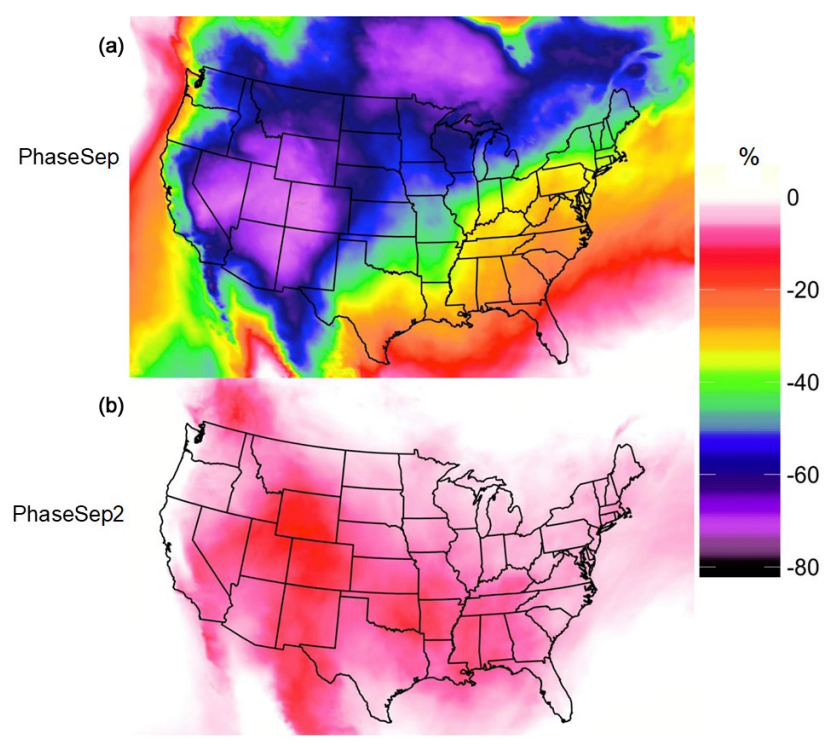

Figure 8. Spatial map of the mean percent relative change in IEPOX-derived SOA for the (a) PhaseSep and (b) PhaseSep2 cases relative to the NonPhaseSep simulation.

ern United States shows a high reduction in IEPOX-derived SOA (Fig. 8), it is not reflected for changes in biogenic SOA, while the high reduction in IEPOX-derived SOA (Fig. 8) in southern Canada is reflected in reductions in biogenic SOA in that region. This spatial variability can be explained by the lower fraction of IEPOX-derived SOA in total biogenic SOA on average in the southwestern United States compared to its higher fraction in southern Ontario (Fig. S3), which is further reduced to some extent in PhaseSep2 (Fig. S3c) and becomes negligible in the PhaseSep case for the southwestern US (Fig. S3b). Hence, the magnitude of changes in biogenic SOA and eventually $\mathrm{PM}_{2.5}$ organic carbon mass (Fig. S4) is dampened as compared to changes in IEPOXderived SOA mass with introduction of phase-separation parameters (Fig. 8).

On average, the largest reduction in biogenic SOA mass at any one grid cell was $40.9 \%$ and occurred over a forested region in southern Ontario near Lake Superior which also exhibits high IEPOX-derived SOA contribution to total biogenic SOA (Fig. S3). For the southeastern United States, modeled average reductions for 2013 SOAS period in IEPOX-derived SOA ranged between $25 \%$ and $30 \%$, translated to a $10 \%-15 \%$ reduction in total biogenic SOA (Fig. 8). The highest average reduction in IEPOX-derived SOA was $74.06 \%$ over Colorado (Fig. 8a). This reduction matters less in terms of overall biogenic SOA reduction due to negligible contribution of IEPOX-derived SOA to total biogenic SOA in the American southwest (Fig. S3). In southern Ontario, where the maximum biogenic SOA reduction in PhaseSep occurred, the average reductions in IEPOX-derived SOA per grid cell ranged from $63 \%$ to $66 \%$. The southern
Ontario region with maximum biogenic SOA reduction had average particle viscosities per grid cell in the range of $\sim 10^{3}$ to $10^{6} \mathrm{Pas}$. The total phase-separation frequency of particles for southern Canada region was $86.3 \%$ of which SSPS was $62.04 \%$ and LLPS was $24.26 \%$. The combination of these factors led to a $52.64 \%$ average reduction in $\gamma_{\text {IEPOX }}$ in PhaseSep, which can be treated as a hypothetical upper bound.

PhaseSep2 led to predicted $\gamma_{\text {IEPOX }}$ values that were more similar to those of NonPhaseSep than PhaseSep; however, there is some small variation in western states. Overall, biogenic SOA mass yields increased by an average of $25.86 \%$ from the PhaseSep simulation for the continental United States. Table S1 in the Supplement shows a modest $4 \%$ improvement in model performance for total $\mathrm{PM}_{2.5}$ OC mass, in the isoprene-abundant southeastern United States with PhaseSep2. The range of phase-separation frequency in semisolid particles per grid cell is still wide in PhaseSep2, i.e., $0.02 \%$ to $55.8 \%$ SSPS. Increased frequency of bulk phase in semi-solid conditions in PhaseSep2 relative to PhaseSep causes much less resistance to reactive uptake, closer to but still more than in NonPhaseSep. This is reflected in the similarity of $\gamma_{\text {IEPOX }}$ between PhaseSep 2 and NonPhaseSep (Fig. 7c). Hence, a smaller difference in IEPOX SOA and biogenic SOA in PhaseSep2 relative to NonPhaseSep occurs, unlike much higher differences observed in PhaseSep (Figs. 8 and S3). Particles in PhaseSep2 adopted a core-shell morphology less frequently than those in PhaseSep, typically causing lower $k_{\text {particle }}$ (Eqs. 13 and 14), which led to reduced reactive uptake of IEPOX compared to PhaseSep.

\section{Comparison to observed data}

Figure 9 and Table S1 show that different consideration of phase state and separation in CMAQ can impact model performance differently. PhaseSep slightly worsened the NMB based on comparison with hourly $\mathrm{PM}_{2.5}$ organic carbon mass SEARCH observations at both the Centreville rural site and urban Jefferson street, Atlanta, site by $\sim-4 \%$. However, this change was marginal in terms of mean bias change in PhaseSep relative to the NonPhaseSep case being $<0.1 \mu \mathrm{g} \mathrm{m}^{-3}$. The sensitivity cases that assumed a higher $H_{\text {org }}$ (HighHorg) and considered LLPS criteria in predicting SSPS (PhaseSep2) resulted in correcting the worsening of model performance observed with the PhaseSep case (Fig. 9 and Table S1). The initial assumption regarding phase separation at high viscosity seems to be approximately as important as the assumption regarding $H_{\text {org }}$ in constraining the impact of phase state and morphology on reactive uptake of IEPOX. This highlights the poorly constrained parameters in models such as $H_{\text {org }}$ assumed as a constant and less understood criterion that might govern phase separation under low $\mathrm{RH}$ or low aerosol water at different $\mathrm{O}: \mathrm{C}$ ratios. 
(a)

Centerville, AL

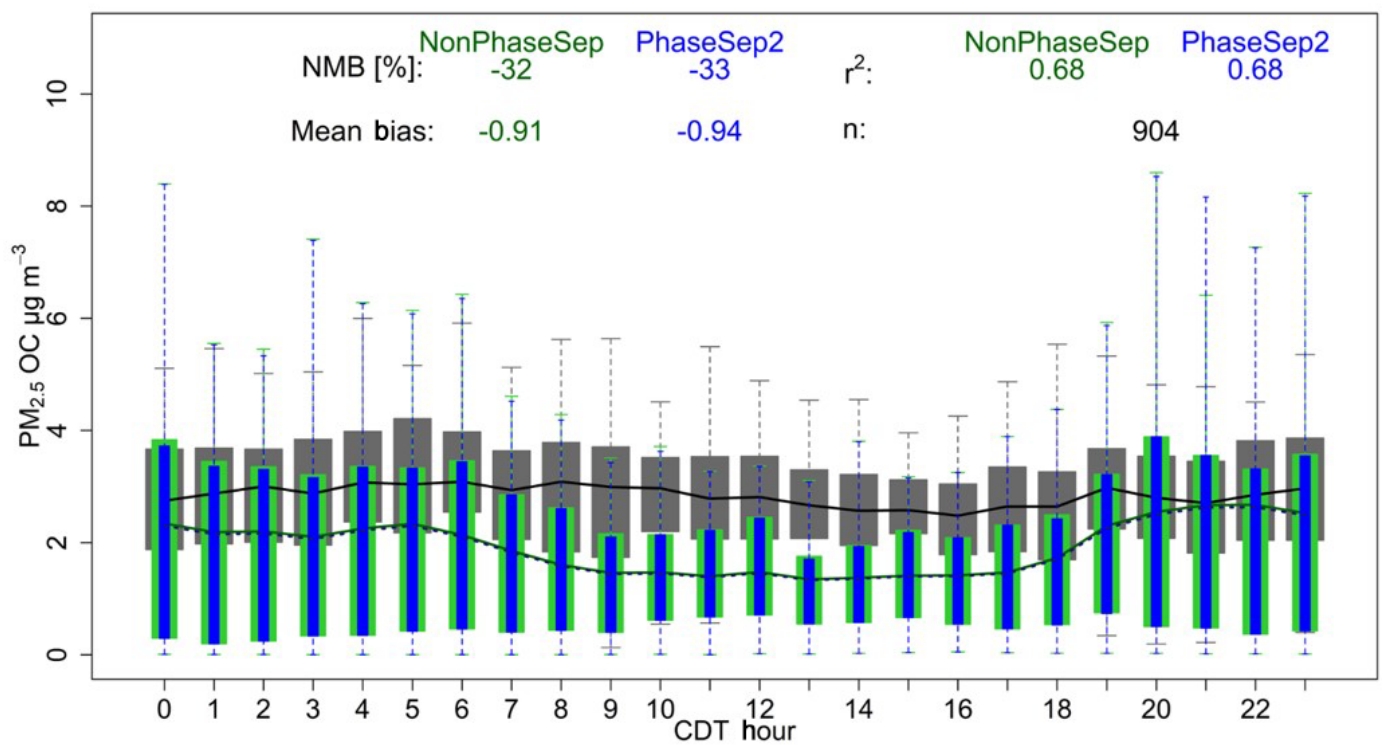

(b)

Jefferson Street, Atlanta, GA

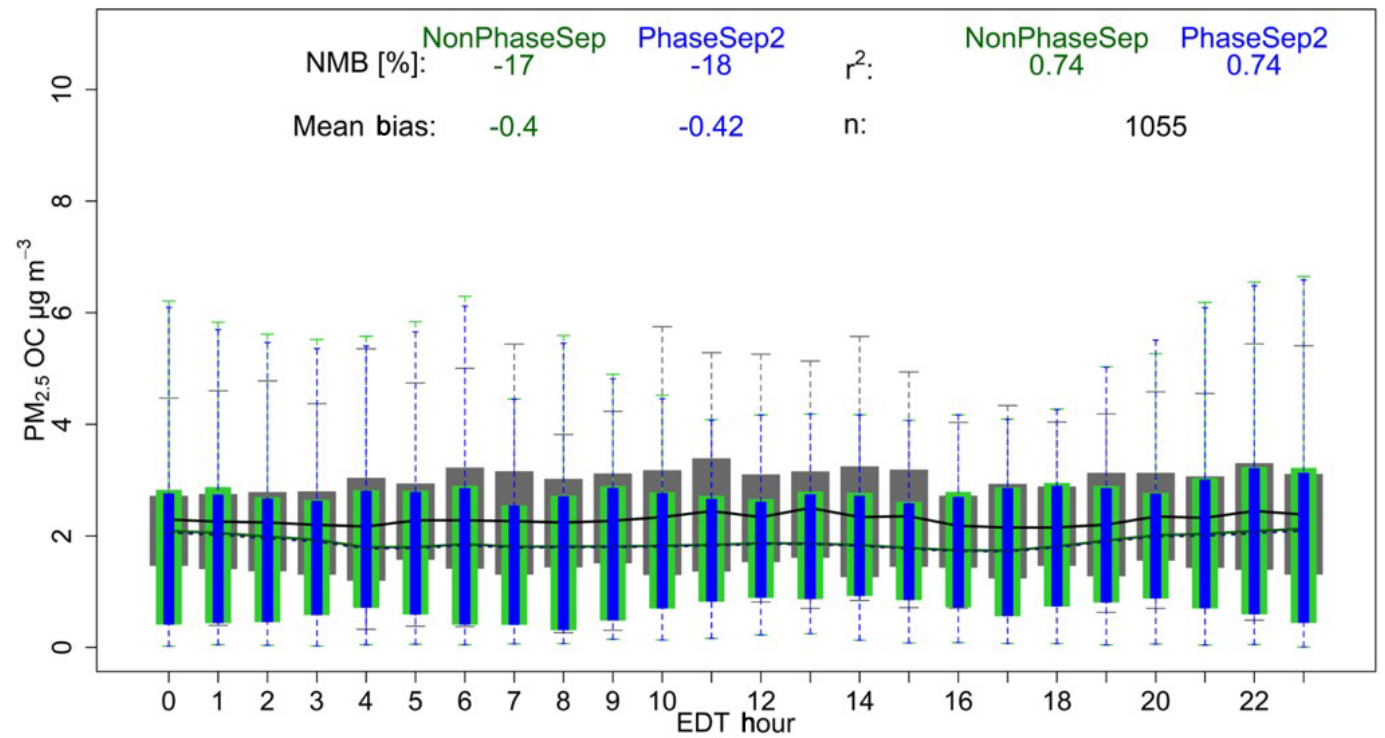

Figure 9. $\mathrm{PM}_{2.5}$ organic carbon (OC) mass $\left(\mu \mathrm{g} \mathrm{m}^{-3}\right)$ as a function of hour of the day. Non-aggregated performance statistics - mean bias $\left(\mu \mathrm{g} \mathrm{m}^{-3}\right), \%$ normalized mean bias (NMB) and Spearman's correlation coefficient $\left(r^{2}\right)$ of NonPhaseSep (green) and PhaseSep2 (blue) cases relative to observed (grey) $\mathrm{PM}_{2.5}$ OC mass for the (a) rural Centreville, AL, site and (b) urban Jefferson Street, Atlanta, GA, site. Bars/shading indicate 25th to 75th percentiles. Extreme bounds of whiskers indicate 5th to 95th percentiles (i.e., $95 \%$ confidence interval). Lines indicate means (dashed line indicates PhaseSep2). $n$ is the number of observation points.

\subsection{Sensitivities}

The reduction in emission sources of $\mathrm{NO}_{x}$ and $\mathrm{SO}_{2}$ impacted aerosol composition and thus the $T_{\mathrm{g}, \mathrm{org}}$. The average $T_{\mathrm{g}, \text { org }}$ for the Emissions Reduction simulation predicted a small but statistically significant ( $p$ value $=2 \times 10^{-16}$ ) increase of $1.5 \mathrm{~K}$ from the PhaseSep simulation, indicating the future emission reductions could result in minor increases in vis- cosity and frequency of phase separation. The overall phaseseparation frequency for this sensitivity was $70.5 \%$ (57.0\% SSPS, $13.5 \%$ LLPS), with predicted viscosities ranging from $6.13 \times 10^{-3}$ to $1.73 \times 10^{11} \mathrm{Pas}$, which was slightly narrower compared to the $\eta_{\text {org }}$ range from the PhaseSep simulation (refer to Sect. 3.1.1). With the implementation of the future reduced $\mathrm{NO}_{x}$ and $\mathrm{SO}_{2}$ emissions, overall, there was a mean $7.85 \%$ reduction in biogenic SOA at the surface level from 


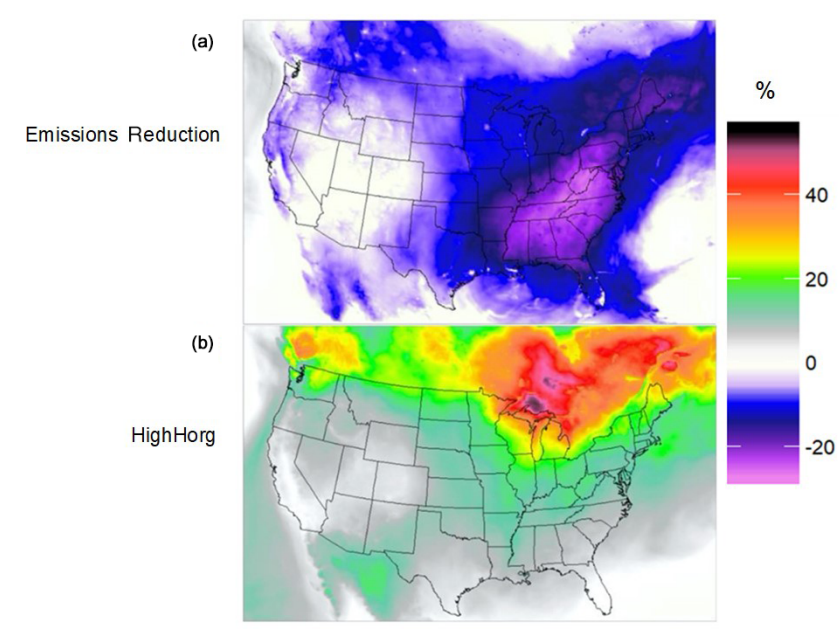

Figure 10. Relative change (\%) in biogenic SOA mass at the surface level from the PhaseSep parameterization for the (a) $\mathrm{NO}_{x}$ and $\mathrm{SO}_{2}$ Emissions Reduction sensitivity simulation and (b) HighHorg sensitivity simulation.

the PhaseSep simulation for the continental United States. As shown in Fig. 10a, the areas with the largest reductions in SOA mass occurred in the American southeast, while a marginal increase in SOA mass that occurred over the Atlantic Ocean and in some sparse areas in northern Canada and the western United States. The American southeast was highly sensitive to the Emissions Reduction sensitivity due to the high concentrations of $\mathrm{SO}_{2}$ from coal-fired power plants and the high concentrations of IEPOX-derived SOA, whose chemistry is driven by particulate sulfate. Figure S5 shows that highest reductions in particulate sulfate occurs in the American southeast, accompanied by a reduction in aerosol liquid water. This drives the reductions in IEPOX-derived SOA as shown in recent literature (Pye et al., 2017) and hence the large reductions in biogenic SOA mass. Also, $\mathrm{NO}_{x}$ reductions in the $\mathrm{NO}_{x}$-limited southeastern United States region essentially result in a larger decrease in biogenic SOA, as shown in Fig. 10a, which is consistent with findings from SENEX aircraft (Edwards et al., 2017) and SOAS ground measurements (Xu et al., 2015) in the southeastern United States.

When increases in $H_{\text {org }}$ were simulated in the HighHorg scenario, it had impacts in opposite directions compared to changes in the Emissions Reduction scenario. This increase in biogenic SOA can simply be attributed to the increased dissolution of IEPOX into the particle phase through the organic coating with a $H_{\text {org }}$ value 3 orders of magnitude higher than that in the PhaseSep simulation. The average $T_{\mathrm{g} \text {,org }}$ in the HighHorg simulation had a similarly small but also statistically significant increase of $1.4 \mathrm{~K}$, with particles being phase separated $68.3 \%$ of the time (55.8\% SSPS, $12.5 \%$ LLPS). Predicted viscosities in this simulation were comparable to the PhaseSep simulation and ranged from
$5.94 \times 10^{-3}$ to $6.10^{11}$ Pas. Overall, biogenic SOA mass increased by an average of $14.19 \%$ at the surface level for this simulation relative to PhaseSep for the continental United States. As shown in Fig. 10b, the regions with the largest increases in biogenic SOA mass were located over boreal forests in Ontario and Quebec, Canada, that correspond to the regions with highest reactive uptake (Fig. $7 \mathrm{~b}$ and c) forming more homogeneous SOA with increased $H_{\text {org }}$.

While modest improvement in model performance of $\mathrm{PM}_{2.5}$ OC by the aforementioned sensitivity simulations (HighHorg and PhaseSep2; see Sect. 3.2.2: "Comparison to observed data") occurs, it does not addresses other major issues in the base CMAQ model performance. Firstly, these updates to phase state and phase-separation considerations only translate to IEPOX SOA, the only explicit parametrization of multiphase reactive uptake in CMAQ. IEPOX SOA also just makes up approximately $12 \%$ of the total $\mathrm{PM}_{2.5} \mathrm{OC}$ mass simulated by CMAQ on an average for the 2013 SOAS period. There are other more important factors introducing major source of uncertainty in models across spatial scales including CMAQ, a very prominent uncertainty being missing representation of species like ONs reported as dominant in the 2013 SOAS by new instrumentation providing higher molecular detail (B. H. Lee et al., 2016; Massoli et al., 2018). Furthermore, field or laboratory studies on a wider suite of SOAs are needed to explicitly parametrize their multiphase chemistry and are still missing in CMAQ. It is a challenge to implement these mechanistic representations of different SOA holistically, without increased computational cost in CMAQ.

\section{Discussion and atmospheric implications}

Current chemical transport models have not accurately accounted for the effects of aerosol composition on phase separation or viscosity. This work has updated the CMAQ model to include parameters to calculate the $T_{\mathrm{g} \text {,org }}$ based on the Gordon-Taylor equation for SOA. This implementation used molar mass and $\mathrm{O}: \mathrm{C}$ ratio of the species, but other parameters could be used. For example, DeRieux et al. (2018) developed a calculation for $T_{g, i}$ based on the number of carbonhydrogen and carbon-oxygen bonds in a molecule. DeRieux et al. (2018) showed their implementation to be in good agreement with implementation provided in this work (Eq. 4) for species with molar masses in the range of those used by CMAQ v5.2.1. This implementation also included parameters to determine whether SOA was phase separated based on its viscosity, $\mathrm{O}: \mathrm{C}$ ratio, sulfate concentrations and the ambient RH. Our updated PhaseSep2 model predicted up to $65.4 \%$ of the time particles would exhibit phase separation at the surface layer, which is in proximity with the $\sim 70 \%$ predicted by Pye et al. (2017) for the isoprene-rich Centerville site in the southeastern United States. PhaseSep overestimated this phase-separation frequency at $\sim 79.3 \%$, indicat- 
ing PhaseSep 2 as a broader and accurate scenario for future implementations as well. This implementation predicts that most of the SOA in the middle and upper troposphere over the United States is phase separated with more organics in a semi-solid or even glassy state with increasing altitude. This is in agreement with previous fieldwork and modeling studies which have found that SOA in the upper troposphere tends to be in a glassy state (Lienhard et al., 2015; Shiraiwa et al., 2017). This work also shows LLPS to be more dominant in the eastern US, with the semi-solid phase state being more prevalent in the western US. This is in agreement with the predominant role of aerosol liquid water driving the liquid phase state and LLPS across the eastern United States, as observed in previous studies (Pye et al., 2017, 2018). The factors driving LLPS and SSPS are also an area that should be further studied due to the fact that the modifying the conditions for LLPS and SSPS led to large differences in IEPOXSOA.

The model predicted that SOA dominated by anthropogenic constituents typically featured thick semi-solid organic coatings surrounding aqueous cores, which caused the reactive uptake of IEPOX to become diffusion limited. Regions that were predicted to have larger fractions of biogenic SOA mass typically featured LLPS morphology that did not produce much of diffusion limitations. These aerosols also resulted in a smaller inorganic core volume increasing the concentrations of nucleophiles and acids, thus enhancing the rate of reaction in presence of abundant aerosol water over oceans but exhibited reduction in SOA over land, though not as much as solid-like particles exhibited. The phaseseparation parameters had the largest impact over the Ohio River valley, southern Canada (more pronounced near Great Lakes) and the American southeast. These areas were also the most sensitive to future emission reductions of $\mathrm{NO}_{x}$ and $\mathrm{SO}_{2}$.

Further experimental and modeling work is required to understand the effects of aerosol phase state on the viscosity of the inorganic core that cause variability in the value of $D_{\text {a }}$ and can subsequently alter the reactive uptake of IEPOX. The combined effect of aerosol acidity and aforementioned higher core viscosity because of IEPOX SOA formation that has a self-limiting impact on IEPOX reactive uptake is also a caveat to be explored further (Zhang et al., 2019). The conditions under which highly viscous SOA will separate from inorganics in a particle or if the particle will remain homogeneously mixed should be further explored as well, given the differences in the frequency of predicted particle-phase separation between the PhaseSep and PhaseSep2 simulations and the implications that this has for the reactive uptake of IEPOX (Table S1). Constraining the viscosity of SOA in low $\mathrm{RH}(<30 \%)$ conditions is also an area that should be further explored to improve model performance. Furthermore, particle morphology in the event of phase-separated organic and inorganic species as "core-shell", "partially engulfed" or "emulsified" (smaller islands of organics in the aqueous inor- ganic core) is driven by the differences in the interfacial surface tensions (Gorkowski et al., 2017). However, developing a computationally efficient method of modeling these alternative particle morphologies in CTMs is an area of ongoing research and needs further exploration. Recent studies have also shown that at very high RH ranges (95\%-100\%), some particles will return to a core-shell morphology (Ham et al., 2019; Renbaum-Wolff et al., 2016). There is also little information on the criteria that drive a particle to adopt a phaseseparated morphology under these conditions. Such variability in particle morphologies may modify the value of $k_{\text {particle }}$ by changing the core volume. It is imperative that these parameters be better constrained in models. Furthermore, there is much uncertainty in the organic shell Henry's law coefficient $\left(H_{\text {org }}\right)$, where higher $H_{\text {org }}$ increases the dissolution of IEPOX into the aerosol. Some of the newly proposed reaction mechanisms leading to the formation of extremely lowvolatile organic compounds (ELVOCs) and organosulfates may also increase the viscosity of the particle but have not been incorporated into this study.

This work paves the way for implementing a more accurate representation of multiphase chemistry of different complex systems on the lines of explicit representation of IEPOX SOA. Multiphase chemistry of other dominant SOA apart from IEPOX SOA, such as monoterpene-derived SOA and ONs derived from both isoprene and monoterpenes, is not incorporated in CMAQ v5.2.1 (Pye et al., 2018; Slade et al., 2019) and should be a focus of future work. This work showed that organic water fraction is the biggest driver of viscosity, though the water abundance was set at a constant $10 \%$ of the inorganic water content to better reflect observed concentrations of organic water during daylight hours relevant to IEPOX SOA chemistry. Organic water uptake, even if higher than the amount assumed here, will still follow the diurnal trend of $\mathrm{RH}$ since it is diverted from the aqueous core that is derived from ISORROPIA-based aerosol water in CMAQ v5.2.1. In this work, the $\mathrm{O}: \mathrm{C}$ ratio of individual organic constituents as listed in Table 1 was used to calculate $T_{\mathrm{g} \text {,org }}$ based on Shiraiwa et al. (2017). The O : C provides an indication of hygroscopicity of different organic species (Pye et al., 2017), but it is only a surrogate. Lack of explicitly representing hydrophobicity or hygroscopic growth of various organic constituents is a limitation in the CMAQ modeling framework that was used. More recently, the degree of diffusivity or uptake of semi-volatile organic compounds (SVOCs) such as isoprene oxidation products and ONs into more viscous or semi-solid particle phase is found to differ. These changes in $\eta_{\text {org }}$ profoundly impact both aerosol growth kinetics and their size distribution dynamics (Vander Wall et al., 2020; Zaveri et al., 2020). To assess the actual impacts of aging and hygroscopic growth under varying conditions, updates in the CMAQ model are required by adding explicit reactive uptake mechanisms for a wider range of non-IEPOX SOAs. 
Performing sensitivity simulations in terms of different assumptions made on determining phase separation or morphology (PhaseSep2 and PhaseSep) is as important as constraining the $H_{\mathrm{org}}$ (HighHorg) factor in the regions with abundant IEPOX-SOA such as the American and Canadian southeast. Incorporating explicit kinetics coupled with thermodynamic calculation of energies governing the mixing state of organic-inorganic aerosol mixtures under different aerosol phase states, as observed from recent and ongoing experimental findings, into atmospheric models such as CMAQ, would lead to more scientifically sound representations of the impact particle-phase state and morphology have on SOA mass predictions.

Code availability. US EPA makes the source code of CMAQ version 5.2.1 model publicly available for download at https: //github.com/USEPA/CMAQ/tree/5.2.1 (last access: 6 November 2019) (US EPA Office of Research and Development; https://doi.org/10.5281/zenodo.1212601). Corresponding author William Vizuete can make the modifications made to the CMAQ source code as part of this work available on request.

Data availability. The emissions and meteorological inputs along with other miscellaneous inputs to run the CMAQ model for the 2013 SOAS episode (1 June 2013 to 15 July 2015) across the continental United States can be downloaded from https://drive. google.com/open?id=1XR6Xp3bZzrZIzNBx-AgjcNCtC_HLlCkZ (last access: 6 November 2019), made available by US EPA and University of North Carolina - Institute of Environment (2019).

Supplement. The supplement related to this article is available online at: https://doi.org/10.5194/acp-20-8201-2020-supplement.

Author contributions. RS and QZR led the writing with WV. RS designed the new PhaseSep methodology along with sensitivity cases to run in consistent consultation with YZ, HOTP, YC, JDS, QZR and WV. QZR implemented the model code and performed the simulations in the regional-scale model with reviews from HOTP. RS analyzed results of simulations with QZR, WV and HZ. FDLH, JAT, AHG and HZ analyzed the SOAS field data. RS and QZR prepared the paper with extensive reviews and edits from $\mathrm{WV}, \mathrm{YZ}, \mathrm{YC}$, HOTP, HZ and JDS.

Competing interests. The authors declare that they have no conflict of interest.

Disclaimer. The U.S. Environmental Protection Agency through its Office of Research and Development collaborated in the research described here. The research has been subjected to Agency administrative review and approved for publication but may not necessarily reflect official Agency policy. The views expressed in this article are those of the authors and do not necessarily represent the views or policies of the U.S. Environmental Protection Agency.

Acknowledgements. A National Science Foundation (NSF) Postdoctoral Fellowship under Atmospheric and Geospace Sciences (AGS-1524731) and the National Institute of Health (NIH) training grant supported Yue Zhang. Haofei Zhang and Allen H. Goldstein were supported by NSF grants AGS-1250569 and AGS-1644406. Felipe D. Lopez-Hilfiker and Joel A. Thornton were supported by a grant from the US Department of Energy Atmospheric System Research Program (DE-SC0018221). Jason D. Surratt, Yuzhi Chen and Yue Zhang were supported by NSF-AGS grant 1703535 . Claudia Mohr (Department of Atmospheric Sciences, University of Washington, Seattle, WA; currently at Department of Environmental Science and Analytical Chemistry, Stockholm University, 106 91 Stockholm, Sweden) and Anna Lutz (Department of Chemistry and Molecular Biology, University of Gothenberg, 41296 Gothenberg, Sweden) are acknowledged for providing the FIGAEROCIMS measurements from the 2013 SOAS campaign. Ben H. Lee (Department of Atmospheric Sciences, University of Washington, Seattle, WA) is also acknowledged for organizing the 2013 SOAS field data.

Financial support. This research has been supported by the NSFAGS (grant nos. AGS-1524731, AGS-1703535, AGS-1250569 and AGS-1644406) and the US Department of Energy Atmospheric System Research Program (grant no. DE-SC0018221).

Review statement. This paper was edited by Yafang Cheng and reviewed by two anonymous referees.

\section{References}

Anttila, T., Kiendler-Scharr, A., Tillmann, R., and Mentel, T. F.: On the Reactive Uptake of Gaseous Compounds by OrganicCoated Aqueous Aerosols: Theoretical Analysis and Application to the Heterogeneous Hydrolysis of $\mathrm{N}_{2} \mathrm{O}_{5}$, J. Phys. Chem. A, 110, 10435-10443, https://doi.org/10.1021/jp062403c, 2006.

Appel, K. W., Napelenok, S. L., Foley, K. M., Pye, H. O. T., Hogrefe, C., Luecken, D. J., Bash, J. O., Roselle, S. J., Pleim, J. E., Foroutan, H., Hutzell, W. T., Pouliot, G. A., Sarwar, G., Fahey, K. M., Gantt, B., Gilliam, R. C., Heath, N. K., Kang, D., Mathur, R., Schwede, D. B., Spero, T. L., Wong, D. C., and Young, J. O.: Description and evaluation of the Community Multiscale Air Quality (CMAQ) modeling system version 5.1, Geosci. Model Dev., 10, 1703-1732, https://doi.org/10.5194/gmd-10-1703-2017, 2017.

Bash, J. O., Baker, K. R., and Beaver, M. R.: Evaluation of improved land use and canopy representation in BEIS v3.61 with biogenic VOC measurements in California, Geosci. Model Dev., 9, 21912207, https://doi.org/10.5194/gmd-9-2191-2016, 2016.

Bateman, A. P., Bertram, A. K., and Martin, S. T.: Hygroscopic Influence on the Semisolid-to-Liquid Transition of Secondary Organic Materials, J. Phys. Chem. A, 119, 4386-4395, https://doi.org/10.1021/jp508521c, 2015a. 
Bateman, A. P., Gong, Z., Liu, P., Sato, B., Cirino, G., Zhang, Y., Artaxo, P., Bertram, A. K., Manzi, A. O., Rizzo, L. V., Souza, R. A. F., Zaveri, R. A., and Martin, S. T.: Sub-micrometre particulate matter is primarily in liquid form over Amazon rainforest, Nat. Geosci., 9, 34, https://doi.org/10.1038/ngeo2599, 2015 b.

Bateman, A. P., Gong, Z., Harder, T. H., de Sá, S. S., Wang, B., Castillo, P., China, S., Liu, Y., O’Brien, R. E., Palm, B. B., Shiu, H.-W., Cirino, G. G., Thalman, R., Adachi, K., Alexander, M. L., Artaxo, P., Bertram, A. K., Buseck, P. R., Gilles, M. K., Jimenez, J. L., Laskin, A., Manzi, A. O., Sedlacek, A., Souza, R. A. F., Wang, J., Zaveri, R., and Martin, S. T.: Anthropogenic influences on the physical state of submicron particulate matter over a tropical forest, Atmos. Chem. Phys., 17, 1759-1773, https://doi.org/10.5194/acp-17-1759-2017, 2017.

Bates, K. H., Crounse, J. D., St. Clair, J. M., Bennett, N. B., Nguyen, T. B., Seinfeld, J. H., Stoltz, B. M., and Wennberg, P. O.: Gas Phase Production and Loss of Isoprene Epoxydiols, J. Phys. Chem. A, 118, 1237-1246, https://doi.org/10.1021/jp4107958, 2014.

Bertram, A. K., Martin, S. T., Hanna, S. J., Smith, M. L., Bodsworth, A., Chen, Q., Kuwata, M., Liu, A., You, Y., and Zorn, S. R.: Predicting the relative humidities of liquid-liquid phase separation, efflorescence, and deliquescence of mixed particles of ammonium sulfate, organic material, and water using the organic-to-sulfate mass ratio of the particle and the oxygen-tocarbon elemental ratio of the organic component, Atmos. Chem. Phys., 11, 10995-11006, https://doi.org/10.5194/acp-11-109952011, 2011.

Bondy, A. L., Craig, R. L., Zhang, Z., Gold, A., Surratt, J. D., and Ault, A. P.: Isoprene-Derived Organosulfates: Vibrational Mode Analysis by Raman Spectroscopy, AcidityDependent Spectral Modes, and Observation in Individual Atmospheric Particles, J. Phys. Chem. A, 122, 303-315, https://doi.org/10.1021/acs.jpca.7b10587, 2018.

Budisulistiorini, S. H., Baumann, K., Edgerton, E. S., Bairai, S. T., Mueller, S., Shaw, S. L., Knipping, E. M., Gold, A., and Surratt, J. D.: Seasonal characterization of submicron aerosol chemical composition and organic aerosol sources in the southeastern United States: Atlanta, Georgia,and Look Rock, Tennessee, Atmos. Chem. Phys., 16, 5171-5189, https://doi.org/10.5194/acp16-5171-2016, 2016.

Budisulistiorini, S. H., Nenes, A., Carlton, A. G., Surratt, J. D., McNeill, V. F., and Pye, H. O. T.: Simulating Aqueous-Phase Isoprene-Epoxydiol (IEPOX) Secondary Organic Aerosol Production During the 2013 Southern Oxidant and Aerosol Study (SOAS), Environ. Sci. Technol., 51, 5026-5034, https://doi.org/10.1021/acs.est.6b05750, 2017.

Carlton, A. G. and Baker, K. R.: Photochemical Modeling of the Ozark Isoprene Volcano: MEGAN, BEIS, and Their Impacts on Air Quality Predictions, Environ. Sci. Technol., 45, 4438-4445, https://doi.org/10.1021/es200050x, 2011.

Carslaw, K. S., Lee, L. A., Reddington, C. L., Pringle, K. J., Rap, A., Forster, P. M., Mann, G. W., Spracklen, D. V., Woodhouse, M. T., Regayre, L. A., and Pierce, J. R.: Large contribution of natural aerosols to uncertainty in indirect forcing, Nature, 503, 67-71, https://doi.org/10.1038/nature12674, 2013.

Chenyakin, Y.: Are diffusion coefficients calculated using the Stokes-Einstein equation combined with viscosities consistent with measured diffusion coefficients of tracer organics within organics-water mediums?, University of British Columbia, https://doi.org/10.14288/1.0166352, 2015.

Cui, T., Zeng, Z., dos Santos, E. O., Zhang, Z., Chen, Y., Zhang, Y., Rose, C. A., Budisulistiorini, S. H., Collins, L. B., Bodnar, W. M., de Souza, R. A. F., Martin, S. T., Machado, C. M. D., Turpin, B. J., Gold, A., Ault, A. P., and Surratt, J. D.: Development of a hydrophilic interaction liquid chromatography (HILIC) method for the chemical characterization of watersoluble isoprene epoxydiol (IEPOX)-derived secondary organic aerosol, Environmental Science: Processes \& Impacts, 20, 1524 1536, https://doi.org/10.1039/C8EM00308D, 2018.

DeRieux, W.-S. W., Li, Y., Lin, P., Laskin, J., Laskin, A., Bertram, A. K., Nizkorodov, S. A., and Shiraiwa, M.: Predicting the glass transition temperature and viscosity of secondary organic material using molecular composition, Atmos. Chem. Phys., 18, 6331-6351, https://doi.org/10.5194/acp-18-6331-2018, 2018.

Docherty, K. S., Stone, E. A., Ulbrich, I. M., DeCarlo, P. F., Snyder, D. C., Schauer, J. J., Peltier, R. E., Weber, R. J., Murphy, S. M., Seinfeld, J. H., Grover, B. D., Eatough, D. J., and Jimenez, J. L.: Apportionment of primary and secondary organic aerosols in southern California during the 2005 study of organic aerosols in riverside (SOAR-1), Environ. Sci. Technol., 42, 7655-7662, https://doi.org/10.1021/es8008166, 2008.

Eddingsaas, N. C., VanderVelde, D. G., and Wennberg, P. O.: Kinetics and products of the acid-catalyzed ring-opening of atmospherically relevant butyl epoxy alcohols, J. Phys. Chem. A, 114, 8106-8113, https://doi.org/10.1021/jp103907c, 2010.

Edwards, P. M., Aikin, K. C., Dube, W. P., Fry, J. L., Gilman, J. B., de Gouw, J. A., Graus, M. G., Hanisco, T. F., Holloway, J., Hübler, G., Kaiser, J., Keutsch, F. N., Lerner, B. M., Neuman, J. A., Parrish, D. D., Peischl, J., Pollack, I. B., Ravishankara, A. R., Roberts, J. M., Ryerson, T. B., Trainer, M., Veres, P. R., Wolfe, G. M., Warneke, C., and Brown, S. S.: Transition from high- to low- $\mathrm{NO}_{x}$ control of night-time oxidation in the southeastern US, Nat. Geosci., 10, 490, https://doi.org/10.1038/ngeo2976, 2017.

Emery, C., Jung, J., Koo, B., and Yarwood, G.: Improvements to CAMx snow cover treatments and Carbon Bond chemical mechanism for winter ozone, UDAQ PO, 480, 52000000001, 2015.

Evoy, E., Maclean, A. M., Rovelli, G., Li, Y., Tsimpidi, A. P., Karydis, V. A., Kamal, S., Lelieveld, J., Shiraiwa, M., Reid, J. P., and Bertram, A. K.: Predictions of diffusion rates of large organic molecules in secondary organic aerosols using the StokesEinstein and fractional Stokes-Einstein relations, Atmos. Chem. Phys., 19, 10073-10085, https://doi.org/10.5194/acp-19-100732019, 2019.

Eyth, A., Zubrow, A., and Mason, R: Technical Support Document (TSD): Preparation of Emissions Inventories for the Version 6.1, 2011 Emissions Modeling Platform, available at: http://www.epa.gov/ttn/chief/emch/2011v6/2011v6.1_ 2018_2025_base_EmisMod_TSD_nov2014_v6.pdf (last access: 20 November 2018), 2014.

Freedman, M. A.: Phase separation in organic aerosol, Chem. Soc. Rev., 46, 7694-7705, https://doi.org/10.1039/C6CS00783J, 2017.

Fulcher, G. S.: Analysis of recent measurements of viscosity of glasses, J. Amer. Ceram. Soc., 8, 339-355, https://doi.org/10.1111/j.1151-2916.1925.tb16731.x, 1925.

Gaston, C. J., Riedel, T. P., Zhang, Z., Gold, A., Surratt, J. D., and Thornton, J. A.: Reactive Uptake of an Isoprene-Derived Epoxy- 
diol to Submicron Aerosol Particles, Environ. Sci. Technol., 48, 11178-11186, https://doi.org/10.1021/es5034266, 2014.

Gordon, M. and Taylor, J.: Ideal Copolymers and the Second-Order Transitions of Synthetic Rubbers. I. NonCrystalline Copolymers, J. Appl. Chem., 2, 493-500, https://doi.org/10.1002/jctb.5010020901, 1952.

Gorkowski, K., Donahue, N. M., and Sullivan, R. C.: Emulsified and liquid-liquid phase-separated states of $\alpha$-pinene secondary organic aerosol determined using aerosol optical tweezers, Environ. Sci. Technol., 51, 12154-12163, https://doi.org/10.1021/acs.est.7b03250, 2017.

Grandey, B. S., Rothenberg, D., Avramov, A., Jin, Q., Lee, H.-H., Liu, X., Lu, Z., Albani, S., and Wang, C.: Effective radiative forcing in the aerosol-climate model CAM5.3-MARC-ARG, Atmos. Chem. Phys., 18, 15783-15810, https://doi.org/10.5194/acp-1815783-2018, 2018.

Grayson, J. W., Zhang, Y., Mutzel, A., Renbaum-Wolff, L., Böge, O., Kamal, S., Herrmann, H., Martin, S. T., and Bertram, A. K.: Effect of varying experimental conditions on the viscosity of $\alpha$-pinene derived secondary organic material, Atmos. Chem. Phys., 16, 6027-6040, https://doi.org/10.5194/acp-166027-2016, 2016.

Grayson, J. W., Evoy, E., Song, M., Chu, Y., Maclean, A., Nguyen, A., Upshur, M. A., Ebrahimi, M., Chan, C. K., Geiger, F. M., Thomson, R. J., and Bertram, A. K.: The effect of hydroxyl functional groups and molar mass on the viscosity of non-crystalline organic and organic-water particles, Atmos. Chem. Phys., 17, 8509-8524, https://doi.org/10.5194/acp-17-8509-2017, 2017.

Guenther, A., Karl, T., Harley, P., Wiedinmyer, C., Palmer, P. I., and Geron, C.: Estimates of global terrestrial isoprene emissions using MEGAN (Model of Emissions of Gases and Aerosols from Nature), Atmos. Chem. Phys., 6, 3181-3210, https://doi.org/10.5194/acp-6-3181-2006, 2006.

Guo, H., Xu, L., Bougiatioti, A., Cerully, K. M., Capps, S. L., Hite Jr., J. R., Carlton, A. G., Lee, S.-H., Bergin, M. H., Ng, N. L., Nenes, A., and Weber, R. J.: Fine-particle water and $\mathrm{pH}$ in the southeastern United States, Atmos. Chem. Phys., 15, 5211-5228, https://doi.org/10.5194/acp-15-5211-2015, 2015.

Ham, S., Babar, Z. B., Lee, J. B., Lim, H.-J., and Song, M.: Liquidliquid phase separation in secondary organic aerosol particles produced from $\alpha$-pinene ozonolysis and $\alpha$-pinene photooxidation with/without ammonia, Atmos. Chem. Phys., 19, 93219331, https://doi.org/10.5194/acp-19-9321-2019, 2019.

Hansen, D. A., Edgerton, E. S., Hartsell, B. E., Jansen, J. J., Kandasamy, N., Hidy, G. M., and Blanchard, C. L.: The Southeastern Aerosol Research and Characterization Study: Part 1 - Overview, J. Air Waste Manag. Assoc., 53, 1460-1471, https://doi.org/10.1080/10473289.2003.10466318, 2003.

Heath, N. K., Pleim, J. E., Gilliam, R. C., and Kang, D.: A simple lightning assimilation technique for improving retrospective WRF simulations, J. Adv. Model. Earth Syst., 8, 1806-1824, https://doi.org/10.1002/2016MS000735, 2016.

Huang, W., Saathoff, H., Pajunoja, A., Shen, X., Naumann, K.H., Wagner, R., Virtanen, A., Leisner, T., and Mohr, C.: $\alpha-$ Pinene secondary organic aerosol at low temperature: chemical composition and implications for particle viscosity, Atmos. Chem. Phys., 18, 2883-2898, https://doi.org/10.5194/acp18-2883-2018, 2018.
Hwang, S.-H., Lee, J. Y., Yi, S.-M., and Kim, H.: Associations of particulate matter and its components with emergency room visits for cardiovascular and respiratory diseases, PLOS ONE, 12, e0183224, https://doi.org/10.1371/journal.pone.0183224, 2017.

Jacobs, M. I., Burke, W. J., and Elrod, M. J.: Kinetics of the reactions of isoprene-derived hydroxynitrates: gas phase epoxide formation and solution phase hydrolysis, Atmos. Chem. Phys., 14, 8933-8946, https://doi.org/10.5194/acp-14-8933-2014, 2014.

Jaques, P. A. and Kim, C. S.: Measurement of total lung deposition of inhaled ultrafine particles in healthy men and women, Inhal. Toxicol., 12, 715-731, https://doi.org/10.1080/08958370050085156, 2000.

Koop, T., Bookhold, J., Shiraiwa, M., and Pöschl, U.: Glass transition and phase state of organic compounds: dependency on molecular properties and implications for secondary organic aerosols in the atmosphere, Phys. Chem. Chem. Phys., 13, 19238-19255, https://doi.org/10.1039/C1CP22617G, 2011.

Krechmer, J. E., Coggon, M. M., Massoli, P., Nguyen, T. B., Crounse, J. D., Hu, W., Day, D. A., Tyndall, G. S., Henze, D. K., Rivera-Rios, J. C., Nowak, J. B., Kimmel, J. R., Mauldin, R. L., Stark, H., Jayne, J. T., Sipilä, M., Junninen, H., Clair, J. M. S., Zhang, X., Feiner, P. A., Zhang, L., Miller, D. O., Brune, W. H., Keutsch, F. N., Wennberg, P. O., Seinfeld, J. H., Worsnop, D. R., Jimenez, J. L., and Canagaratna, M. R.: Formation of Low Volatility Organic Compounds and Secondary Organic Aerosol from Isoprene Hydroxyhydroperoxide Low-NO Oxidation, Environ. Sci. Technol., 49, 10330-10339, https://doi.org/10.1021/acs.est.5b02031, 2015.

Lee, B. H., Mohr, C., Lopez-Hilfiker, F. D., Lutz, A., Hallquist, M., Lee, L., Romer, P., Cohen, R. C., Iyer, S., Kurtén, T., Hu, W., Day, D. A., Campuzano-Jost, P., Jimenez, J.-L., Xu, L., Ng, N. L., Guo, H., Weber, R. J., Wild, R. J., Brown, S. S., Koss, A., de Gouw, J., Olson, K., Goldstein, A. H., Seco, R., Kim, S., McAvey, K., Shepson, P. B., Starn, T., Baumann, K., Edgerton, E. S., Liu, J., Shilling, J. E., Miller, D. O., Brune, W. H., Schobesberger, S., D'Ambro, E. L., and Thornton, J. A.: Highly functionalized organic nitrates in the southeast United States: Contribution to secondary organic aerosol and reactive nitrogen budgets, P. Natl. Acad. Sci. USA, 113, 1516-1521, 2016.

Lee, L. A., Reddington, C. L., and Carslaw, K. S.: On the relationship between aerosol model uncertainty and radiative forcing uncertainty, P. Natl. Acad. Sci. USA, 113, 5820-5827, https://doi.org/10.1073/pnas.1507050113, 2016.

Liao, J., Froyd, K. D., Murphy, D. M., Keutsch, F. N., Yu, G., Wennberg, P. O., St Clair, J. M., Crounse, J. D., Wisthaler, A., Mikoviny, T., Jimenez, J. L., Campuzano-Jost, P., Day, D. A., Hu, W., Ryerson, T. B., Pollack, I. B., Peischl, J., Anderson, B. E., Ziemba, L. D., Blake, D. R., Meinardi, S., and Diskin, G.: Airborne measurements of organosulfates over the continental U.S, J. Geophys. Res.-Atmos., 120, 2990-3005, https://doi.org/10.1002/2014JD022378, 2015.

Lienhard, D. M., Huisman, A. J., Krieger, U. K., Rudich, Y., Marcolli, C., Luo, B. P., Bones, D. L., Reid, J. P., Lambe, A. T., Canagaratna, M. R., Davidovits, P., Onasch, T. B., Worsnop, D. R., Steimer, S. S., Koop, T., and Peter, T.: Viscous organic aerosol particles in the upper troposphere: diffusivity-controlled water uptake and ice nucleation?, Atmos. Chem. Phys., 15, 1359913613, https://doi.org/10.5194/acp-15-13599-2015, 2015. 
Lopez-Hilfiker, F. D., Mohr, C., D’Ambro, E. L., Lutz, A., Riedel, T. P., Gaston, C. J., Iyer, S., Zhang, Z., Gold, A., Surratt, J. D., Lee, B. H., Kurten, T., Hu, W. W., Jimenez, J., Hallquist, M., and Thornton, J. A.: Molecular Composition and Volatility of Organic Aerosol in the Southeastern U.S.: Implications for IEPOX Derived SOA, Environ. Sci. Technol., 50, 2200-2209, https://doi.org/10.1021/acs.est.5b04769, 2016.

Maclean, A. M., Butenhoff, C. L., Grayson, J. W., Barsanti, K., Jimenez, J. L., and Bertram, A. K.: Mixing times of organic molecules within secondary organic aerosol particles: a global planetary boundary layer perspective, Atmos. Chem. Phys., 17, 13037-13048, https://doi.org/10.5194/acp-17-130372017, 2017.

Marais, E. A., Jacob, D. J., Jimenez, J. L., Campuzano-Jost, P., Day, D. A., Hu, W., Krechmer, J., Zhu, L., Kim, P. S., Miller, C. C., Fisher, J. A., Travis, K., Yu, K., Hanisco, T. F., Wolfe, G. M., Arkinson, H. L., Pye, H. O. T., Froyd, K. D., Liao, J., and McNeill, V. F.: Aqueous-phase mechanism for secondary organic aerosol formation from isoprene: application to the southeast United States and co-benefit of $\mathrm{SO}_{2}$ emission controls, Atmos. Chem. Phys., 16, 1603-1618, https://doi.org/10.5194/acp16-1603-2016, 2016.

Marcolli, C., Luo, B., and Peter, T.: Mixing of the Organic Aerosol Fractions: Liquids as the Thermodynamically Stable Phases, J. Phys. Chem. A, 108, 2216-2224, https://doi.org/10.1021/jp0360801, 2004.

Marsh, A., Petters, S. S., Rothfuss, N. E., Rovelli, G., Song, Y. C., Reid, J. P., and Petters, M. D.: Amorphous phase state diagrams and viscosity of ternary aqueous organic/organic and inorganic/organic mixtures, Phys. Chem. Chem. Phys., 20, 1508615097, https://doi.org/10.1039/c8cp00760h, 2018.

Martin, S. T.: Phase Transitions of Aqueous Atmospheric Particles, Chem. Rev., 100, 3403-3454, https://doi.org/10.1021/cr990034t, 2000

Massoli, P., Stark, H., Canagaratna, M. R., Krechmer, J. E., Xu, L., Ng, N. L., Mauldin, R. L., Yan, C., Kimmel, J., Misztal, P. K., Jimenez, J. L., Jayne, J. T., and Worsnop, D. R.: Ambient Measurements of Highly Oxidized Gas-Phase Molecules during the Southern Oxidant and Aerosol Study (SOAS) 2013, ACS Earth and Space Chemistry, 2, 653-672, https://doi.org/10.1021/acsearthspacechem.8b00028, 2018.

Murphy, B. N., Woody, M. C., Jimenez, J. L., Carlton, A. M. G., Hayes, P. L., Liu, S., Ng, N. L., Russell, L. M., Setyan, A., Xu, L., Young, J., Zaveri, R. A., Zhang, Q., and Pye, H. O. T.: Semivolatile POA and parameterized total combustion SOA in CMAQv5.2: impacts on source strength and partitioning, Atmos. Chem. Phys., 17, 11107-11133, https://doi.org/10.5194/acp-1711107-2017, 2017.

Nozière, B., Kalberer, M., Claeys, M., Allan, J., D’Anna, B., Decesari, S., Finessi, E., Glasius, M., Grgić, I., Hamilton, J. F., Hoffmann, T., Iinuma, Y., Jaoui, M., Kahnt, A., Kampf, C. J., Kourtchev, I., Maenhaut, W., Marsden, N., Saarikoski, S., Schnelle-Kreis, J., Surratt, J. D., Szidat, S., Szmigielski, R., and Wisthaler, A.: The molecular identification of organic compounds in the atmosphere: state of the art and challenges, Chem. Rev., 115, 3919-3983, https://doi.org/10.1021/cr5003485, 2015.

O’Brien, R. E., Wang, B., Kelly, S. T., Lundt, N., You, Y., Bertram, A. K., Leone, S. R., Laskin, A., and Gilles, M. K.: Liquid-liquid phase separation in aerosol particles: imaging at the nanometer scale, Environ. Sci. Technol., 49, 4995-5002, https://doi.org/10.1021/acs.est.5b00062, 2015.

Pajunoja, A., Malila, J., Hao, L., Joutsensaari, J., Lehtinen, K. E. J., and Virtanen, A.: Estimating the Viscosity Range of SOA Particles Based on Their Coalescence Time, Aerosol Sci. Technol., 48, i-iv, https://doi.org/10.1080/02786826.2013.870325, 2014.

Paulot, F., Crounse, J. D., Kjaergaard, H. G., Kürten, A., St Clair, J. M., Seinfeld, J. H., and Wennberg, P. O.: Unexpected epoxide formation in the gas-phase photooxidation of isoprene, Science, 325, 730-733, https://doi.org/10.1126/science.1172910, 2009.

Price, H. C., Mattsson, J., Zhang, Y., Bertram, A. K., Davies, J. F., Grayson, J. W., Martin, S. T., O’Sullivan, D., Reid, J. P., Rickards, A. M. J., and Murray, B. J.: Water diffusion in atmospherically relevant $\alpha$-pinene secondary organic material, Chem. Sci., 6, 4876-4883, https://doi.org/10.1039/c5sc00685f, 2015.

Pye, H. O. T., Pinder, R. W., Piletic, I. R., Xie, Y., Capps, S. L., Lin, Y. H., Surratt, J. D., Zhang, Z., Gold, A., Luecken, D. J., Hutzell, W. T., Jaoui, M., Offenberg, J. H., Kleindienst, T. E., Lewandowski, M., and Edney, E. O.: Epoxide pathways improve model predictions of isoprene markers and reveal key role of acidity in aerosol formation, E and T Contents, 47, 1105611064, https://doi.org/10.1021/es402106h, 2013.

Pye, H. O. T., Murphy, B. N., Xu, L., Ng, N. L., Carlton, A. G., Guo, H., Weber, R., Vasilakos, P., Appel, K. W., Budisulistiorini, S. H., Surratt, J. D., Nenes, A., Hu, W., Jimenez, J. L., Isaacman-VanWertz, G., Misztal, P. K., and Goldstein, A. H.: On the implications of aerosol liquid water and phase separation for organic aerosol mass, Atmos. Chem. Phys., 17, 343-369, https://doi.org/10.5194/acp-17-343-2017, 2017.

Pye, H. O. T., Zuend, A., Fry, J. L., Isaacman-VanWertz, G., Capps, S. L., Appel, K. W., Foroutan, H., Xu, L., Ng, N. L., and Goldstein, A. H.: Coupling of organic and inorganic aerosol systems and the effect on gas-particle partitioning in the southeastern US, Atmos. Chem. Phys., 18, 357-370, https://doi.org/10.5194/acp18-357-2018, 2018.

Regayre, L. A., Pringle, K. J., Lee, L. A., Rap, A., Browse, J., Mann, G. W., Reddington, C. L., Carslaw, K. S., Booth, B. B. B., and Woodhouse, M. T.: The Climatic Importance of Uncertainties in Regional Aerosol-Cloud Radiative Forcings over Recent Decades, J. Climate, 28, 6589-6607, https://doi.org/10.1175/JCLI-D-15-0127.1, 2015.

Reid, J. P., Bertram, A. K., Topping, D. O., Laskin, A., Martin, S. T., Petters, M. D., Pope, F. D., and Rovelli, G.: The viscosity of atmospherically relevant organic particles, Nat. Commun., 9, 956, https://doi.org/10.1038/s41467-018-03027-z, 2018.

Renbaum-Wolff, L., Grayson, J. W., Bateman, A. P., Kuwata, M., Sellier, M., Murray, B. J., Shilling, J. E., Martin, S. T., and Bertram, A. K.: Viscosity of $\alpha$-pinene secondary organic material and implications for particle growth and reactivity, P. Natl. Acad. Sci. USA, 110, 8014-8019, https://doi.org/10.1073/pnas.1219548110, 2013.

Renbaum-Wolff, L., Song, M., Marcolli, C., Zhang, Y., Liu, P. F., Grayson, J. W., Geiger, F. M., Martin, S. T., and Bertram, A. K.: Observations and implications of liquid-liquid phase separation at high relative humidities in secondary organic material produced by $\alpha$-pinene ozonolysis without inorganic salts, Atmos. Chem. Phys., 16, 7969-7979, https://doi.org/10.5194/acp16-7969-2016, 2016. 
Riedel, T. P., Lin, Y.-H., Zhang, Z., Chu, K., Thornton, J. A., Vizuete, W., Gold, A., and Surratt, J. D.: Constraining condensed-phase formation kinetics of secondary organic aerosol components from isoprene epoxydiols, Atmos. Chem. Phys., 16, 1245-1254, https://doi.org/10.5194/acp-161245-2016, 2016.

Riemer, N., Vogel, H., Vogel, B., Anttila, T., Kiendler-Scharr, A., and Mentel, T. F.: Relative importance of organic coatings for the heterogeneous hydrolysis of $\mathrm{N}_{2} \mathrm{O}_{5}$ during summer in Europe, J. Geophys. Res.-Atmos., 114, D17307, https://doi.org/10.1029/2008JD011369, 2009.

Riva, M., Chen, Y., Zhang, Y., Lei, Z., Olson, N. E., Boyer, H. C., Narayan, S., Yee, L. D., Green, H. S., Cui, T., Zhang, Z., Baumann, K., Fort, M., Edgerton, E., Budisulistiorini, S. H., Rose, C. A., Ribeiro, I. O., e Oliveira, R. L., dos Santos, E. O., Machado, C. M. D., Szopa, S., Zhao, Y., Alves, E. G., de Sá, S. S., Hu, W., Knipping, E. M., Shaw, S. L., Duvoisin Junior, S., de Souza, R. A. F., Palm, B. B., Jimenez, J.-L., Glasius, M., Goldstein, A. H., Pye, H. O. T., Gold, A., Turpin, B. J., Vizuete, W., Martin, S. T., Thornton, J. A., Dutcher, C. S., Ault, A. P., and Surratt, J. D.: Increasing Isoprene Epoxydiol-to-Inorganic Sulfate Aerosol Ratio Results in Extensive Conversion of Inorganic Sulfate to Organosulfur Forms: Implications for Aerosol Physicochemical Properties, Environ. Sci. Technol., 53, 86828694, https://doi.org/10.1021/acs.est.9b01019, 2019.

Ruiz, L. H. and Yarwood, G.: Interactions between organic aerosol and $\mathrm{NO}_{y}$ : Influence on oxidant production, Final report for AQRP project, 12-012, 2013, available at: http://aqrp.ceer.utexas.edu/projectinfoFY12_13/12-012/ 12-012\%20Final\%20Report.pdf last access: 10 May 2020.

Ryder, O. S., Ault, A. P., Cahill, J. F., Guasco, T. L., Riedel, T. P., Cuadra-Rodriguez, L. A., Gaston, C. J., Fitzgerald, E., Lee, C., Prather, K. A., and Bertram, T. H.: On the role of particle inorganic mixing state in the reactive uptake of $\mathrm{N}_{2} \mathrm{O}_{5}$ to ambient aerosol particles, Environ. Sci. Technol., 48, 1618-1627, https://doi.org/10.1021/es4042622, 2014.

Schmedding, R., Ma, M., Zhang, Y., Farrell, S., Pye, H. O. T., Chen, Y., Wang, C.-T., Rasool, Q. Z., Budisulistiorini, S., Ault, A. P., Surratt, J. and Vizuete, W.: $\alpha$-Pinene-Derived organic coatings on acidic sulfate aerosol impacts secondary organic aerosol formation from isoprene in a box model, Atmos. Environ., 213, 456462, https://doi.org/10.1016/j.atmosenv.2019.06.005, 2019.

Shiraiwa, M., Li, Y., Tsimpidi, A. P., Karydis, V. A., Berkemeier, T., Pandis, S. N., Lelieveld, J., Koop, T., and Pöschl, U.: Global distribution of particle phase state in atmospheric secondary organic aerosols, Nat. Commun., 8, 15002, https://doi.org/10.1021/acs.est.9b01196, 2017.

Slade, J. H., Ault, A. P., Bui, A., Ditto, J., Lei, Z., Bondy, A. L., Olson, N. E., Cook, R. D., Desrochers, S. J., Harvey, R.M., Erickson, M. H., Wallace, H. W., Alvarez, S. L., Flynn, J. H., Boor, B. E., Petrucci, G. A., Gentner, D. R., Griffin, R. J., and Shepson, P. B.: Bouncier particles at night: biogenic secondary organic aerosol chemistry and sulfate drive diel variations in the aerosol phase in a mixed forest, Environ. Sci. Technol., 53, 4977-4987, https://doi.org/10.1021/acs.est.8b07319, 2019.

Song, M., Liu, P. F., Hanna, S. J., Li, Y. J., Martin, S. T., and Bertram, A. K.: Relative humidity-dependent viscosities of isoprene-derived secondary organic material and atmospheric implications for isoprene-dominant forests, Atmos.
Chem. Phys., 15, 5145-5159, https://doi.org/10.5194/acp-155145-2015, 2015.

Song, M., Liu, P. F., Hanna, S. J., Zaveri, R. A., Potter, K., You, Y., Martin, S. T., and Bertram, A. K.: Relative humiditydependent viscosity of secondary organic material from toluene photo-oxidation and possible implications for organic particulate matter over megacities, Atmos. Chem. Phys., 16, 8817-8830, https://doi.org/10.5194/acp-16-8817-2016, 2016.

Song, M., Ham, S., Andrews, R. J., You, Y., and Bertram, A. K.: Liquid-liquid phase separation in organic particles containing one and two organic species: importance of the average O:C, Atmos. Chem. Phys., 18, 12075-12084, https://doi.org/10.5194/acp-18-12075-2018, 2018.

Surratt, J. D., Murphy, S. M., Kroll, J. H., Ng, N. L., Hildebrandt, L., Sorooshian, A., Szmigielski, R., Vermeylen, R., Maenhaut, W., Claeys, M., Flagan, R. C., and Seinfeld, J. H.: Chemical composition of secondary organic aerosol formed from the photooxidation of isoprene, J. Phys. Chem. A, 110, 9665-9690, https://doi.org/10.1021/jp061734m, 2006.

Surratt, J. D., Lewandowski, M., Offenberg, J. H., Jaoui, M., Kleindienst, T. E., Edney, E. O., and Seinfeld, J. H.: Effect of Acidity on Secondary Organic Aerosol Formation from Isoprene, Environ. Sci. Technol., 41, 5363-5369, https://doi.org/10.1021/es0704176, 2007.

Surratt, J. D., Chan, A. W. H., Eddingsaas, N. C., Chan, M., Loza, C. L., Kwan, A. J., Hersey, S. P., Flagan, R. C., Wennberg, P. O., and Seinfeld, J. H.: Reactive intermediates revealed in secondary organic aerosol formation from isoprene, P. Natl. Acad. Sci., 107, 6640-6645, https://doi.org/10.1073/pnas.0911114107, 2010.

Tamman, G. and Hesse, W.: The dependence of viscosity upon the temperature of supercooled liquids, Z. Anorg. Allg. Chem, 156, 245-257, 1926.

Ullmann, D. A., Hinks, M. L., Maclean, A. M., Butenhoff, C. L., Grayson, J. W., Barsanti, K., Jimenez, J. L., Nizkorodov, S. A., Kamal, S., and Bertram, A. K.: Viscosities, diffusion coefficients, and mixing times of intrinsic fluorescent organic molecules in brown limonene secondary organic aerosol and tests of the Stokes-Einstein equation, Atmos. Chem. Phys., 19, 14911503, https://doi.org/10.5194/acp-19-1491-2019, 2019.

US EPA and University of North Carolina-Institute of Environment: soas_2013_cb6, available at: https://drive.google.com/drive/ folders/1XR6Xp3bZzrZIzNBx-AgjcNCtC_HLlCkZ, last access: 6 November 2019.

US EPA Office of Research and Development: CMAQ (Version 5.2.1), Zenodo, https://doi.org/10.5281/zenodo.1212601, 30 March 2018.

Vander Wall, A. C., Perraud, V., Wingen, L. M., and FinlaysonPitts, B. J.: Evidence for a kinetically controlled burying mechanism for growth of high viscosity secondary organic aerosol, Environ. Sci.: Processes \& Impacts, 22, 66-83, https://doi.org/10.1039/C9EM00379G, 2020.

Virtanen, A., Joutsensaari, J., Koop, T., Kannosto, J., Yli-Pirilä, P., Leskinen, J., Mäkelä, J. M., Holopainen, J. K., Pöschl, U., Kulmala, M., Worsnop, D. R., and Laaksonen, A.: An amorphous solid state of biogenic secondary organic aerosol particles, Nature, 467, 824-827, https://doi.org/10.1038/nature09455, 2010.

Vogel, H.: The law of relation between the viscosity of liquids and the temperature, Phys. Z., 22, 645-646, 1921. 
Xu, L., Suresh, S., Guo, H., Weber, R. J., and Ng, N. L.: Aerosol characterization over the southeastern United States using high-resolution aerosol mass spectrometry: spatial and seasonal variation of aerosol composition and sources with a focus on organic nitrates, Atmos. Chem. Phys., 15, 7307-7336, https://doi.org/10.5194/acp-15-7307-2015, 2015.

Xu, L., Middlebrook, A. M., Liao, J., de Gouw, J. A., Guo, H., Weber, R. J., Nenes, A., Lopez-Hilfiker, F. D., Lee, B. H., Thornton, J. A., Brock, C. A., Neuman, J. A., Nowak, J. B., Pollack, I. B., Welti, A., Graus, M., Warneke, C., and $\mathrm{Ng}, \mathrm{N}$. L.: Enhanced formation of isoprene-derived organic aerosol in sulfur-rich power plant plumes during Southeast Nexus, J. Geophys. Res.-Atmos., 121, 11137-11153, https://doi.org/10.1002/2016jd025156, 2016.

Xu, L., Pye, H. O. T., He, J., Chen, Y., Murphy, B. N., and Ng, N. L.: Experimental and model estimates of the contributions from biogenic monoterpenes and sesquiterpenes to secondary organic aerosol in the southeastern United States, Atmos. Chem. Phys., 18, 12613-12637, https://doi.org/10.5194/acp-18-126132018, 2018.

Yarwood, G., Whitten, G. Z., Jung, J., Heo, G., and Allen, D. T.: Development, evaluation and testing of version 6 of the Carbon Bond chemical mechanism (CB6), The University of Texas, Austin, 2010.

You, Y., Renbaum-Wolff, L., Carreras-Sospedra, M., Hanna, S. J., Hiranuma, N., Kamal, S., Smith, M. L., Zhang, X., Weber, R. J., Shilling, J. E., Dabdub, D., Martin, S. T., and Bertram, A. K.: Images reveal that atmospheric particles can undergo liquidliquid phase separations, P. Natl. Acad. Sci. USA, 109, 1318813193, https://doi.org/10.1073/pnas.1206414109, 2012.

You, Y., Smith, M. L., Song, M., Martin, S. T., and Bertram, A. K.: Liquid-liquid phase separation in atmospherically relevant particles consisting of organic species and inorganic salts, Int. Rev. Phys. Chem., 33, 43-77, https://doi.org/10.1080/0144235X.2014.890786, 2014.

Yu, C. H., Zhu, X., and Fan, Z.: Spatial/Temporal Variations and Source Apportionment of VOCs Monitored at Community Scale in an Urban Area, edited by: Zhang, Y., PLoS ONE, 9, e95734, https://doi.org/10.1371/journal.pone.0095734, 2014.

Zanobetti, A. and Schwartz, J.: The Effect of Fine and Coarse Particulate Air Pollution on Mortality: A National Analysis, Environ. Health Persp., 117, 898-903, https://doi.org/10.1289/ehp.0800108, 2009.

Zaveri, R. A., Shilling, J. E., Zelenyuk, A., Zawadowicz, M. A., Suski, K., China, S., Bell, D. M., Veghte, D., and Laskin, A.: Particle-Phase Diffusion Modulates Partitioning of Semivolatile Organic Compounds to Aged Secondary Organic Aerosol, Environ. Sci. Technol., 54, 2563-3050, https://doi.org/10.1021/acs.est.9b05514, 2020.

Zhang, H., Surratt, J. D., Lin, Y. H., Bapat, J., and Kamens, R. M.: Effect of relative humidity on SOA formation from isoprene/NO photooxidation: enhancement of 2-methylglyceric acid and its corresponding oligoesters under dry conditions, Atmos. Chem. Phys., 11, 6411-6424, https://doi.org/10.5194/acp11-6411-2011, 2011.
Zhang, H., Yee, L. D., Lee, B. H., Curtis, M. P., Worton, D. R., Isaacman-VanWertz, G., Offenberg, J. H., Lewandowski, M., Kleindienst, T. E., and Beaver, M. R.: Monoterpenes are the largest source of summertime organic aerosol in the southeastern United States, P. Natl. Acad. Sci., 115, 2038-2043, https://doi.org/10.1073/pnas.1717513115, 2018.

Zhang, Q., Jimenez, J. L., Canagaratna, M. R., Allan, J. D., Coe, H., Ulbrich, I., Alfarra, M. R., Takami, A., Middlebrook, A. M., Sun, Y. L., Dzepina, K., Dunlea, E., Docherty, K., DeCarlo, P. F., Salcedo, D., Onasch, T., Jayne, J. T., Miyoshi, T., Shimono, A., Hatakeyama, S., Takegawa, N., Kondo, Y., Schneider, J., Drewnick, F., Borrmann, S., Weimer, S., Demerjian, K., Williams, P., Bower, K., Bahreini, R., Cottrell, L., Griffin, R. J., Rautiainen, J., Sun, J. Y., Zhang, Y. M., and Worsnop, D. R.: Ubiquity and dominance of oxygenated species in organic aerosols in anthropogenically-influenced Northern Hemisphere midlatitudes, Geophys. Res. Lett., 34, L13801, https://doi.org/10.1029/2007gl029979, 2007.

Zhang, Y., Sanchez, M. S., Douet, C., Wang, Y., Bateman, A. P., Gong, Z., Kuwata, M., Renbaum-Wolff, L., Sato, B. B., Liu, P. F., Bertram, A. K., Geiger, F. M., and Martin, S. T.: Changing shapes and implied viscosities of suspended submicron particles, Atmos. Chem. Phys., 15, 7819-7829, https://doi.org/10.5194/acp15-7819-2015, 2015.

Zhang, Y., Chen, Y., Lambe, A. T., Olson, N. E., Lei, Z., Craig, R. L., Zhang, Z., Gold, A., Onasch, T. B., Jayne, J. T., Worsnop, D. R., Gaston, C. J., Thornton, J. A., Vizuete, W., Ault, A. P., and Surratt, J. D.: Effect of the Aerosol-Phase State on Secondary Organic Aerosol Formation from the Reactive Uptake of IsopreneDerived Epoxydiols (IEPOX), Environ. Sci. Technol. Lett., 5, 167-174, https://doi.org/10.1021/acs.estlett.8b00044, 2018.

Zhang, Y., Chen, Y., Lei, Z., Olson, N. E., Riva, M., Koss, A. R., Zhang, Z., Gold, A., Jayne, J. T., Worsnop, D. R., Onasch, T. B., Kroll, J. H., Turpin, B. J., Ault, A. P., and Surratt, J. D.: Joint Impacts of Acidity and Viscosity on the Formation of Secondary Organic Aerosol from Isoprene Epoxydiols (IEPOX) in Phase Separated Particles, ACS Earth and Space Chemistry, 3, 2646-2658, https://doi.org/10.1021/acsearthspacechem.9b00209, 2019.

Zuend, A. and Seinfeld, J. H.: Modeling the gas-particle partitioning of secondary organic aerosol: the importance of liquidliquid phase separation, Atmos. Chem. Phys., 12, 3857-3882, https://doi.org/10.5194/acp-12-3857-2012, 2012.

Zuend, A., Marcolli, C., Luo, B. P., and Peter, T.: A thermodynamic model of mixed organic-inorganic aerosols to predict activity coefficients, Atmos. Chem. Phys., 8, 4559-4593, https://doi.org/10.5194/acp-8-4559-2008, 2008. 